\title{
Multi-omic profiling of pituitary thyrotropic cells and progenitors
}

\author{
Alexandre Z. Daly ${ }^{1} \mathbb{D}$, Lindsey A. Dudley ${ }^{1} \mathbb{D}$, Michael T. Peel ${ }^{2,3} \mathbb{B}$, Stephen A. Liebhaber ${ }^{1,2} \mathbb{D}$, \\ Stephen C. J. Parker ${ }^{4}$ (iD and Sally A. Camper ${ }^{1 *}$ (D)
}

\begin{abstract}
Background: The pituitary gland is a neuroendocrine organ containing diverse cell types specialized in secreting hormones that regulate physiology. Pituitary thyrotropes produce thyroid-stimulating hormone (TSH), a critical factor for growth and maintenance of metabolism. The transcription factors POU1F1 and GATA2 have been implicated in thyrotrope fate, but the transcriptomic and epigenomic landscapes of these neuroendocrine cells have not been characterized. The goal of this work was to discover transcriptional regulatory elements that drive thyrotrope fate.
\end{abstract}

Results: We identified the transcription factors and epigenomic changes in chromatin that are associated with differentiation of POU1F1-expressing progenitors into thyrotropes using cell lines that represent an undifferentiated Poulf1 lineage progenitor (GHF-T1) and a committed thyrotrope line that produces TSH (TaT1). We compared RNAseq, ATAC-seq, histone modification (H3K27Ac, H3K4Me1, and H3K27Me3), and POU1F1 binding in these cell lines. POU1F1 binding sites are commonly associated with bZIP transcription factor consensus binding sites in GHF-T1 cells and Helix-Turn-Helix (HTH) or basic Helix-Loop-Helix (bHLH) factors in TaT1 cells, suggesting that these classes of transcription factors may recruit or cooperate with POU1F1 binding at unique sites. We validated enhancer function of novel elements we mapped near Cga, Pitx1, Gata2, and Tshb by transfection in TaT1 cells. Finally, we confirmed that an enhancer element near Tshb can drive expression in thyrotropes of transgenic mice, and we demonstrate that GATA2 enhances Tshb expression through this element.

Conclusion: These results extend the ENCODE multi-omic profiling approach to the pituitary gland, which should be valuable for understanding pituitary development and disease pathogenesis.

Keywords: TSH, Chromatin, bZIP, bHLH, bHTH, POU1F1, GATA2

\section{Background}

Recent genome-wide association studies (GWAS) have begun to identify loci that are associated with sporadic pituitary adenomas and variation in normal height, but the genes associated with many of these loci are unknown [1-3]. Nearly $90 \%$ of GWAS hits are in noncoding regions, making it difficult to transition from genetic mapping to biological mechanism [4]. Recent studies

\footnotetext{
* Correspondence: scamper@med.umich.edu

'Department Human Genetics, University of Michigan Medical School, Ann Arbor, MI 48109, USA

Full list of author information is available at the end of the article
}

that identify enhancer regions by undertaking large-scale functional genomic annotation of noncoding elements like Encyclopedia of DNA Elements (ENCODE) have begun to yield a better understanding of some complex phenotypes and diseases. Dense molecular profiling maps of the transcriptome and epigenome have been generated for more than 250 cell lines and 150 tissues, but pituitary cell lines or tissues were not included. This represents a major limitation, as the cell types that comprise the pituitary gland secrete hormones responsible for growth (growth hormone secreted by somatotropes), reproduction (gonadotropins secreted by gonadotropes),

(C) The Author(s). 2021 Open Access This article is licensed under a Creative Commons Attribution 4.0 International License, which permits use, sharing, adaptation, distribution and reproduction in any medium or format, as long as you give appropriate credit to the original author(s) and the source, provide a link to the Creative Commons licence, and indicate if changes were made. The images or other third party material in this article are included in the article's Creative Commons licence, unless indicated otherwise in a credit line to the material. If material is not included in the article's Creative Commons licence and your intended use is not permitted by statutory regulation or exceeds the permitted use, you will need to obtain permission directly from the copyright holder. To view a copy of this licence, visit http://creativecommons.org/licenses/by/4.0/. The Creative Commons Public Domain Dedication waiver (http://creativecommons.org/publicdomain/zero/1.0/) applies to the data made available in this article, unless otherwise stated in a credit line to the data. 
adrenal gland function and the stress response $(\mathrm{ACTH}$ secreted by corticotropes), lactation (prolactin secreted by lactotropes), and thyroid gland function (thyroidstimulating hormone secreted by thyrotropes). Epigenomic and gene expression data are emerging for somatotropes, gonadotropes, and corticotropes, but there is very little available data on thyrotropes [5-8].

Thyrotropes represent $\sim 5 \%$ of cells in the pituitary gland, and their function is to express and secrete thyroid-stimulating hormone (TSH or thyrotropin), which regulates thyroid gland development and thyroid hormone production. These hormones are essential for normal growth and metabolism. Up to $12 \%$ of the US population has abnormal levels of thyrotropin [9]. The incidence of secondary hypothyroidism is estimated to be $1: 20,000$ to $1: 80,000$ individuals [10]. Research into the regulation of thyrotrope differentiation and function is relevant to this public health problem.

A cascade of transcription factors is responsible for the differentiation of the major pituitary hormone-producing cell types. The transcription factors associated with thyrotrope development and function are POU1F1, GATA2, ISL1, PITX1, and PITX2. The pituitary transcription factor POU1F1 is essential for the differentiation of growth hormone, prolactin, and TSH-producing cells [11]. It binds to the promoters of $G h, P r l$, and $T s h b$ to activate gene expression [12-16]. Defects in the POU1F1 gene cause severe growth insufficiency and hypothyroidism in humans and mice $[11,17]$. POU1F1 and GATA2 act synergistically to activate Tshb expression through promoter-proximal elements $[13,18]$. Defects in GATA2 and ISL1 reduce thyrotrope differentiation in mice, but they do not appear to ablate it [1921]. Finally, induction of Pitx 2 deficiency in thyrotropes using Tshb-cre causes moderate growth deficiency, blunted TSH response to hypothyroidism challenge, and elevated Pitx1 expression [22]. This suggests that Pitx2 has a role in thyrotrope function that overlaps with the related Pitxl gene [23, 24]. Despite the important role of Poulf1 in thyrotrope development and function, little is known about the gene regulatory network of POU1F1 in progenitors or thyrotropes.

Due to the scarcity of the thyrotrope cell type, classical genomic techniques are challenging to apply. Hormoneproducing cell lines have been invaluable for understanding changes in chromatin and gene expression that occur during development $[5,25]$. To discover thyrotrope-specific regulatory elements and potential drivers of differentiation, we generated and compared the transcriptome (RNA-seq), open chromatin (ATAC-seq), histone modification (CUT\&RUN for H3K27Ac, H3K4Me1, and H3K27Me3), and transcription factor binding (CUT\&RUN for POU1F1) in two mouse cell lines, a POU1F1-expressing pituitary precursor cell line that does not express any hormones, GHF-T1, to a

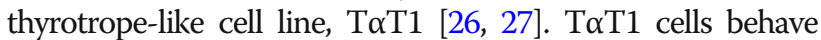
much like endogenous thyrotropes in that they respond to
TRH and retinoids, and they secrete TSH in response to diurnal cues [28-30]. Finally, we evaluated putative enhancer elements for function using transfection assays in TaT1 cells and genetically engineered mice. Together, these studies extend ENCODE-like multi-omic analyses to generate reference maps of gene regulation for cell types critical for growth and metabolism.

\section{Results \\ Comparison of transcriptomes}

To identify candidate factors that drive the differentiation of thyrotropes, we performed RNA sequencing on the GHF-T1 and T $\alpha$ T1 cell lines. There were many differences in their transcriptomes, consistent with their distinctive morphology, growth rate, and hormone secretion properties (Fig. 1a). Eighty-two percent of genes were differentially expressed $($ FDR $<0.01)$. Poulf1 expression levels were nearly twice as high in ToT1 cells (160 FPKM) relative to GHF-T1 cells (85 FPKM). Other SV40 immortalized pituitary cell lines vary ten-fold in Poulf1 expression levels, but there was no correlation with differentiation state [31]. As expected, Cga and Tshb were expressed in T $\alpha \mathrm{T} 1$ (3557 and 11 FPKM, respectively) but negligibly expressed in GHF-T1 cells (1.4 and 0 FPKM, respectively). The GHF-T1 cells had elevated expression of the transcription factors Gli3, Pax3, Foxg1, and others (Table 1). TaT1 cells had elevated expression of Gata2 and Isl1, as expected, and Lhx3, Rxrg, Neurod4, Insm1, and other transcription factors were also expressed at significantly higher levels than in GHFT1 cells. Some of the differences in transcription factor gene expression were dramatic, i.e., in the range of $8-10$ fold, but others were more modest, like Isl1 (1.3x). Isl1 is critical for driving thyrotrope fate, but it is expressed in both progenitors and differentiated cells [19].

To uncover pathways with altered gene expression in these cell lines, we performed GO term (gene ontology) enrichment analysis on the top 5\% of the most differentially expressed genes (by log-2 fold-change) in both lines [32, 33]. The GO terms enriched in GHFT1 cells were broadly related to development and morphogenesis (Table 2). Genes contributing to these GO terms include genes from the GLI family that are targets of hedgehog signaling (Gli2, Gli3, Glipr1, Glipr2, Glis2, Glis3), BMPs (Bmp1, Bmp4, Bmp5, Bmpr1a, Bmpr2, Bmper, Bmp2k), and FGFs (Fgf5, Fgf7, Fgf8, Fgf10, and Fgf21). Elevated expression of these factors in GHFT1 cells is consistent with the underlying the importance of sonic hedgehog, BMP, and FGF signaling in early pituitary development [34-36]. In contrast, the genes with elevated expression in TaT1 cells were enriched for GO terms related to nervous system development and synapse formation. This may be attributable to the fact that the hormone secretory cells in the pituitary gland are excitable and 

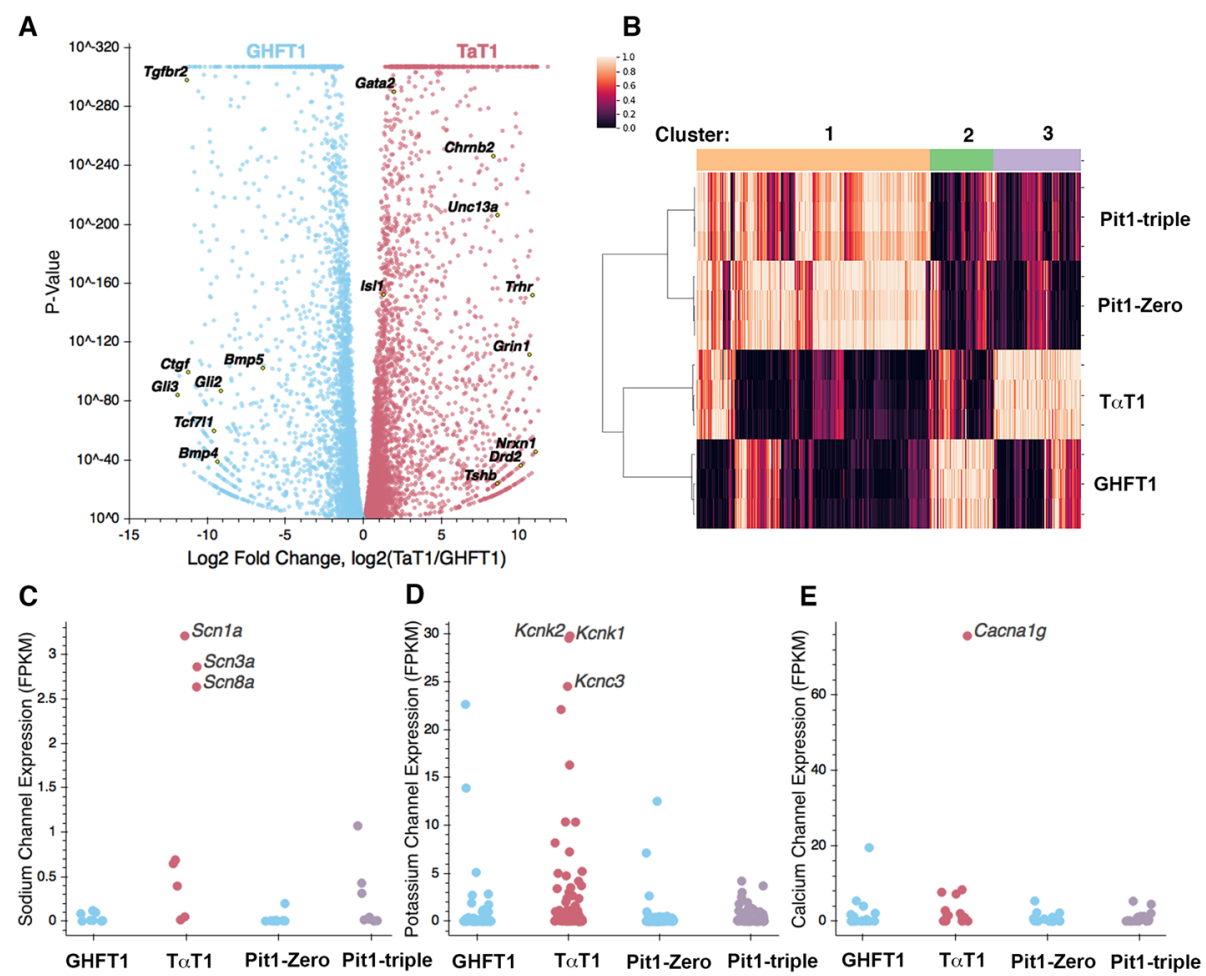

Fig. 1 a Volcano plot of differential gene expression for GHF-T1 compared to TaT1 cells. Genes with elevated expression in GHF-T1 cells are colored blue, and those elevated in TaT1 cells are colored red. Labeled genes represent key factors and genes associated with GO terms in Table 2. $\mathbf{b}$ Heatmap showing similarly and differentially expressed genes across GHF-T1, TaT1, Pit1-Zero, and Pit1-Triple cells. Genes associated with each cluster are presented in Supplemental Table 1. c FPKM values of neuronal sodium channel genes. $\mathbf{d}$ FPKM values of potassium channel genes. e FPKM values of calcium channel genes. $N=3 /$ cell line

fire action potentials, which are altered in response to hypothalamic input and exhibit characteristic patterns of hormone release [37]. In addition, stimulus-secretion coupling also involves interconnection of homotypic networks [38]. Some genes enriched in T $\alpha \mathrm{T} 1$ cells that contribute to these neuronal-like GO terms are neurexin 1 (Nrxn1), genes of the glutamate receptor family (Grin1, Grina, Grin2d, Grin3a), and the synaptic regulator Unc13a. KEGG pathway enrichment analysis revealed an increase in neuroactive ligand-receptor interaction in T $\alpha \mathrm{T} 1$ cells, consistent with the enrichment in GO terms found.

The function of several members of the bHLH family of transcription factors, including Ascl1, Neurod4, and Neurod1, has been investigated in pituitary development [39]. Seventy-one of the ninety-three known bHLH factors are differentially expressed between GHF-T1 and TaT1 cells (FDR $<0.05) ;$ Neurod4 and Ascl1 are expressed at higher levels in T $\alpha \mathrm{T} 1$ cells (Supplemental Table 2). Ascl1 is essential for development of all hormone-producing cell types in fish pituitary, and in mice, Ascl1 loss of function causes reduced production of Pomc, Lhb, and Fshb [39, 40]. However, these reports conflict on whether thyrotropes are affected by Ascl1 deficiency. We performed TSH immunostaining on pituitaries from Ascl1-null mice and did not detect a reduction in thyrotropes at e18.5 (Supplemental Figure 1), suggesting Ascl1 is not required for thyrotrope cell specification. Repressive bHLH genes of the ID family had the highest expression in both of the cell lines, and the role of these genes has not been investigated.

We compared gene expression profiles that we obtained from GHF-T1 and T $\alpha$ T1 cells with those of other SV40transformed pituitary cell lines, Pit1-zero and Pit1-triple cells (Fig. 1b) [31]. Pit1-zero and Pit1-triple cells were transformed using the same Pou1f1 regulatory elements as the GHF-T1 cell line. Pit1-zero cells express Pou1f1, but none of POU1F1's downstream hormone genes, whereas Pit1-triple cells express Poulf1 and all three POU1F1dependent hormones, GH, PRL, and TSH. In the ToT1 cell line, we found a statistically significant increase in the expression of sodium channel genes $(p$ value $=0.002)$ and potassium channel genes ( $p$ value $=2.9 \mathrm{e}-05)$, but not in calcium channel genes as a group $(p$ value $=0.26)$ (Fig. 1c-e). The most highly expressed sodium channel genes in ToT1 cells are Scn1a, Scn8a, and Scn3a. Three sodium channel genes (Scn1a, Scn8a, and Scn9a) are also expressed in the Pit1-Triple cell line, the only other 
Table 1 Differentially expressed transcription factors (FDR $<5 \times 10^{-14}$ )

\begin{tabular}{|c|c|c|c|c|c|}
\hline \multicolumn{3}{|c|}{ GHFT1 cells } & \multicolumn{3}{|c|}{ TaT1 cells } \\
\hline Gene & Log2 fold-change & Rank & Gene & Log2 fold-change & Rank \\
\hline Gli3 & 11.90 & 1 & Lhx3 & 11.04 & 8 \\
\hline Pax3 & 10.95 & 12 & Rxrg & 10.74 & 25 \\
\hline Zfh $\times 4$ & 10.74 & 21 & $\operatorname{lnsm1}$ & 10.67 & 30 \\
\hline Foxg1 & 10.59 & 26 & Neurod4 & 10.56 & 37 \\
\hline Zfp57 & 10.51 & 29 & Sox3 & 10.23 & 55 \\
\hline Hoxc13 & 10.29 & 40 & $\mathrm{FeV}$ & 10.18 & 57 \\
\hline$K d m 5 D$ & 10.19 & 48 & Myt11 & 9.93 & 72 \\
\hline Hmga2 & 10.15 & 53 & Scrt2 & 9.90 & 77 \\
\hline Ms $\times 2$ & 10.11 & 54 & Zfp641 & 9.39 & 126 \\
\hline Runx 1 & 10.07 & 55 & Scrt1 & 9.15 & 145 \\
\hline Rhox10 & 9.94 & 60 & Zic3 & 8.96 & 168 \\
\hline Mecom & 9.84 & 68 & En2 & 8.95 & 169 \\
\hline Tead2 & 9.65 & 80 & $\operatorname{Lin} 28 b$ & 8.82 & 184 \\
\hline $\operatorname{Vax} 1$ & 9.58 & 85 & Pax5 & 8.61 & 205 \\
\hline Tcf7/1 & 9.57 & 87 & Zfp709 & 8.52 & 218 \\
\hline Hoxal & 9.52 & 91 & Prdm16 & 8.30 & 249 \\
\hline Tcf24 & 9.46 & 95 & Pouzf2 & 8.15 & 268 \\
\hline Hoxc9 & 9.35 & 104 & Zim 1 & 7.92 & 301 \\
\hline Maf & 9.32 & 106 & Nhlh1 & 7.85 & 312 \\
\hline Pousf3 & 9.16 & 112 & Foxl2 & 7.82 & 317 \\
\hline Gli2 & 9.13 & 117 & $|s| 1$ & 1.3 & 3896 \\
\hline
\end{tabular}

hormone-expressing cell lineage we studied. The most highly expressed potassium channel genes in TaT1 cells are Kcnc3, Kcnq2, Kcnk1, and Kcnk2. G protein-gated ion channels are involved in regulated hormone secretion. This marked increase in ion channel genes in the T $\alpha \mathrm{T} 1$ cells is consistent with their GO terms associated with synapses and neuron formation and function. The only calcium channel gene with differential expression was Cacna1g, which is highly expressed in T $\alpha \mathrm{T} 1$ cells relative to the other three cell lines.

\section{Chromatin landscape around thyrotrope-signature genes}

To assess genome-wide changes in the chromatin landscape associated with thyrotrope differentiation, we performed Cleavage Under Target and Release using Nuclease (CUT\&RUN) for three major histone marks: H3K27Ac, H3K4Me1, and H3K27Me3 [41]. The presence of both H3K27Ac and H3K4Me1 mark active enhancers, while H3K27Me3 marks repressed regions [4244]. We also performed an Assay for TransposaseAccessible Chromatin with High-Throughput Sequencing (ATAC-seq), a method for profiling regions of accessible chromatin, which are often regulatory [45]. The results for three selected genes, Isl1, Gli3, and Rxrg, are shown in Fig. 2. We chose Isl1 because of its important role in thyrotrope and gonadotrope fate [19], Gli3 for its role in hypothalamic and pituitary development in humans, [17], and Rxrg because of its role in thyrotrope function and retinoic acid regulation of gene expression [46, 47]. Also, Gli3 and Rxrg are the most and secondmost differentially expressed transcription factors in the GHF-T1 and T $\alpha \mathrm{T} 1$ cells, respectively. These data (called tracks) reveal that Isl1 is expressed in both cell lines and has extensive H3K27Ac, H3K4Me1, and ATAC-seq signal across the locus, revealing putative active enhancers and areas of open chromatin. For example, the stretch of H3K4Me1 and H3K27Ac signal covering the last intron and penultimate exon of Isl1 could be an enhancer (Fig. 2a).

We visualized the expression and chromatin architecture around genes that are differentially expressed in the precursor and differentiated cell lines. Gli3 is strongly expressed in GHF-T1 cells and has many H3K27Ac, H3K4Me1, and ATAC-seq peaks, revealing active enhancers in areas of open chromatin (Fig. 2b). By contrast, Gli3 is not expressed in T $\alpha \mathrm{T} 1$ cells. The chromatin

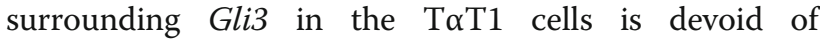
H3K27Ac, H3K4Me1, and ATAC-seq peaks and is covered with $\mathrm{H} 3 \mathrm{~K} 27 \mathrm{Me} 3$, a mark of active repression. This shows that Gli3 is actively repressed in the T $\alpha \mathrm{T} 1$ cell 
Table 2 Gene ontology term enrichment

\begin{tabular}{|c|c|c|c|c|c|c|c|c|c|c|c|c|c|c|c|}
\hline \multicolumn{8}{|c|}{ GHFT1 cells } & \multicolumn{8}{|c|}{ TaT1 cells } \\
\hline \multirow[t]{2}{*}{ Gene } & \multicolumn{5}{|c|}{ Structure and development $^{1}$} & \multicolumn{2}{|c|}{ Expression } & \multirow[t]{2}{*}{ Gene } & \multicolumn{5}{|c|}{ Synapse development and function ${ }^{2}$} & \multicolumn{2}{|c|}{ Expression } \\
\hline & $A$ & B & $\mathrm{C}$ & D & $\mathrm{E}$ & GHFT1 & TaT1 & & $\mathrm{F}$ & G & $\mathrm{H}$ & 1 & $J$ & GHFT1 & TaT1 \\
\hline Cyr61 & $x$ & $x$ & $x$ & $x$ & $x$ & 117.1 & 0.5 & Nrxn1 & $x$ & $x$ & $x$ & $x$ & $x$ & 0.0 & 4.2 \\
\hline Edn1 & $x$ & $x$ & $x$ & $x$ & $x$ & 7.3 & 0.0 & Unc13a & $x$ & $x$ & $x$ & $x$ & $x$ & 0.0 & 19.8 \\
\hline Bmp4 & $x$ & $x$ & $x$ & $x$ & $x$ & 6.8 & 0.0 & Drd2 & $x$ & $x$ & & $x$ & $x$ & 0.0 & 12.4 \\
\hline Tgfbr2 & $x$ & $x$ & $x$ & $x$ & $x$ & 65.1 & 0.0 & Chrnb2 & $x$ & $x$ & & $x$ & $x$ & 0.0 & 12.7 \\
\hline Fgfio & $x$ & $x$ & $x$ & $x$ & $x$ & 1.1 & 0.0 & Grin1 & $x$ & $x$ & & $x$ & $x$ & 0.0 & 20.5 \\
\hline Gli3 & $x$ & $x$ & $X$ & $X$ & $x$ & 13.4 & 0.0 & Syt4 & $x$ & $X$ & & $X$ & $x$ & 0.0 & 86.3 \\
\hline Mef2C & $x$ & $x$ & $x$ & $x$ & $x$ & 7.6 & 0.0 & Grin3a & $x$ & $x$ & & $x$ & $x$ & 0.0 & 11.4 \\
\hline Cav1 & $x$ & $x$ & $x$ & $x$ & $x$ & 10.1 & 0.0 & Snap25 & $x$ & $x$ & & $x$ & $x$ & 0.1 & 107.4 \\
\hline Bmp5 & $x$ & $x$ & $x$ & $x$ & $x$ & 3.8 & 0.0 & Sez6 & $x$ & $x$ & $x$ & $x$ & $x$ & 0.0 & 39.8 \\
\hline Ctgf & $x$ & $x$ & $X$ & $X$ & $x$ & 40.3 & 0.0 & Gabrg2 & $x$ & $x$ & $X$ & $X$ & $X$ & 0.0 & 13.0 \\
\hline Gli2 & $x$ & $x$ & $x$ & $x$ & $x$ & 4.2 & 0.0 & Pclo & $x$ & $x$ & $x$ & $x$ & $x$ & 0.0 & 4.0 \\
\hline Gata6 & $X$ & $x$ & $X$ & $x$ & $x$ & 1.2 & 0.0 & Atp2b2 & & & $X$ & $x$ & & 0.0 & 9.4 \\
\hline Tbx20 & $x$ & $x$ & $x$ & $x$ & $x$ & 2.2 & 0.0 & Chrna4 & $x$ & $x$ & & & $x$ & 0.0 & 3.4 \\
\hline Ms $\times 2$ & $x$ & $x$ & $x$ & $x$ & $x$ & 20.1 & 0.0 & Shisa6 & $x$ & $x$ & & & $x$ & 0.0 & 11.3 \\
\hline Yap1 & $x$ & $x$ & $x$ & $x$ & $x$ & 40.3 & 0.2 & Lrrc4C & & & $x$ & $x$ & & 0.0 & 1.7 \\
\hline Sfrp1 & $x$ & $x$ & $x$ & $x$ & $x$ & 7.1 & 0.0 & Thy1 & & & & $x$ & & 0.0 & 23.3 \\
\hline$H I x$ & $x$ & $x$ & $x$ & $x$ & $x$ & 1.5 & 0.0 & Glra3 & $x$ & $x$ & $x$ & & $x$ & 0.0 & 28.1 \\
\hline Cxcl12 & $x$ & X & $X$ & $X$ & $x$ & 4.2 & 0.0 & Adgfb 1 & & & $x$ & $x$ & & 0.0 & 9.5 \\
\hline Pax3 & $x$ & $x$ & $x$ & $x$ & $x$ & 9.1 & 0.0 & Grial & $x$ & $x$ & & & $x$ & 0.0 & 11.7 \\
\hline Fn1 & $x$ & $x$ & $x$ & $x$ & $x$ & 611.8 & 1.0 & Lgi1 & & & & $x$ & & 0.0 & 1.1 \\
\hline
\end{tabular}

${ }^{1}$ The top five GO terms associated with the top $5 \%$ of the most differentially expressed genes (log 2-fold-change) in GHFT1 cells are $\mathrm{A}=$ animal organ development, $\mathrm{B}=$ anatomical structure development, $\mathrm{C}=$ anatomical structure morphogenesis, $\mathrm{D}=$ multicellular organism development, $\mathrm{E}=$ system development $X$ 's illustrate the association of each gene with a GO term. Expression is given in FPKM

${ }^{2}$ The top five $\mathrm{GO}$ terms associated with TaT1 cells are: $\mathrm{F}=$ synaptic signaling, $\mathrm{G}=$ trans-synaptic signaling, $\mathrm{H}=$ synapse organization, $\mathrm{I}=$ nervous system development, $\mathrm{J}=$ anterograde trans-synaptic signaling

line. Conversely, $R x r g$, a gene whose deletion in mice is associated with thyroid hormone resistance [46], is highly expressed in TaT1 cells but not in GHF-T1 cells (Fig. 2c). Consistent with this, in TaT1 cells the Rxrg locus is decorated with H3K27Ac, H3K4Me1, and ATAC-seq peaks, whereas the GHF-T1 line has no such peaks, and shows active repression of Rxrg, with a broad H3K27Me3 signal. Additional tracks for selected genes that are expressed at similar levels, higher in GHFT1, or higher in T $\alpha \mathrm{T} 1$ are presented in Supplemental Figures 2, 3 and 4, respectively.

We used ChromHMM to annotate different chromatin states based on H3K27Ac, H3K4Me1, H3K27Me3, and ATAC-seq signal [48]. Iterating over increasing numbers of possible states, we found that 11 states best captured the chromatin architecture within these two cell lines (Supplemental Figure 5). Of these states, two had both H3K4Me1 and H3K27Ac, predicting active enhancers. The difference between the two states was the presence or absence of an ATAC-seq signal, meaning one state represented open, active enhancers, while the other represented active enhancers in a more closed state.

\section{POU1F1 binding}

We performed CUT\&RUN for POU1F1 in both the GHF-T1 and T $\alpha$ T1 cell lines to identify similarities and differences in POU1F1 binding at these two stages of differentiation. We present three specific examples of POU1F1 binding. Pou1f1 has two enhancers, a proximal $(5.6 \mathrm{~kb})$, early-stage enhancer bound by PROP1, and a distal $(10 \mathrm{~kb})$, late-stage enhancer. POU1F1 binds the distal enhancer and drives its own expression in an auto-regulatory fashion [49, 50]. In both cell lines, CUT\&RUN shows extensive POU1F1 binding across the Poulf1 promoter-proximal region and both the early and late enhancers (Fig. 3a). The Tcf7l1 gene is an example of elevated expression and preferential POU1F1 binding in GHF-T1 cells relative to TaT1 cells (Fig. 3b). TCF7L1 is important for hypothalamic-pituitary development and function in humans and mice [51]. Selective 


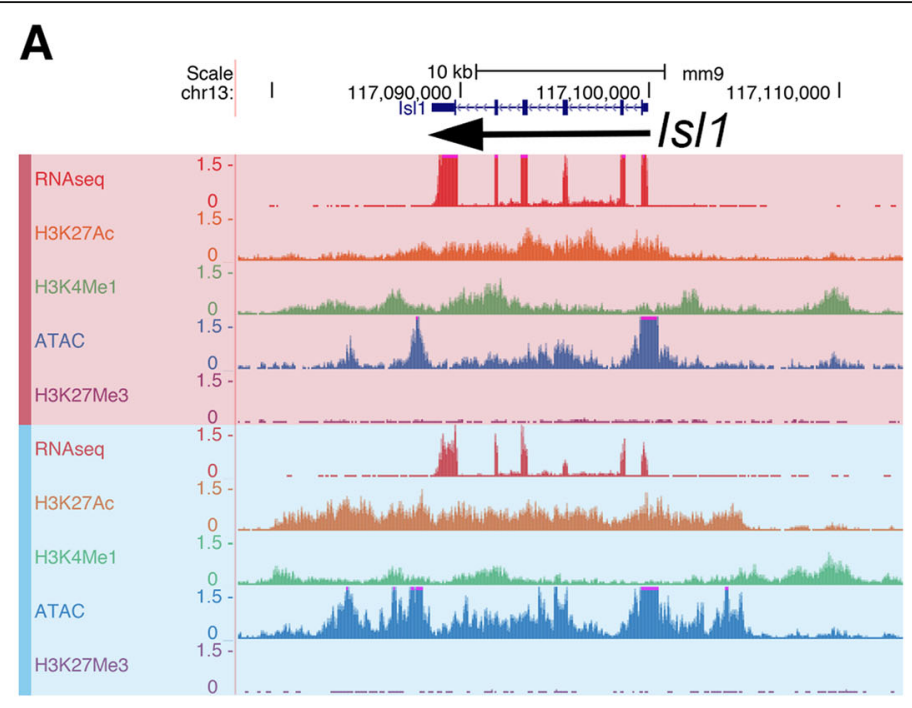

B

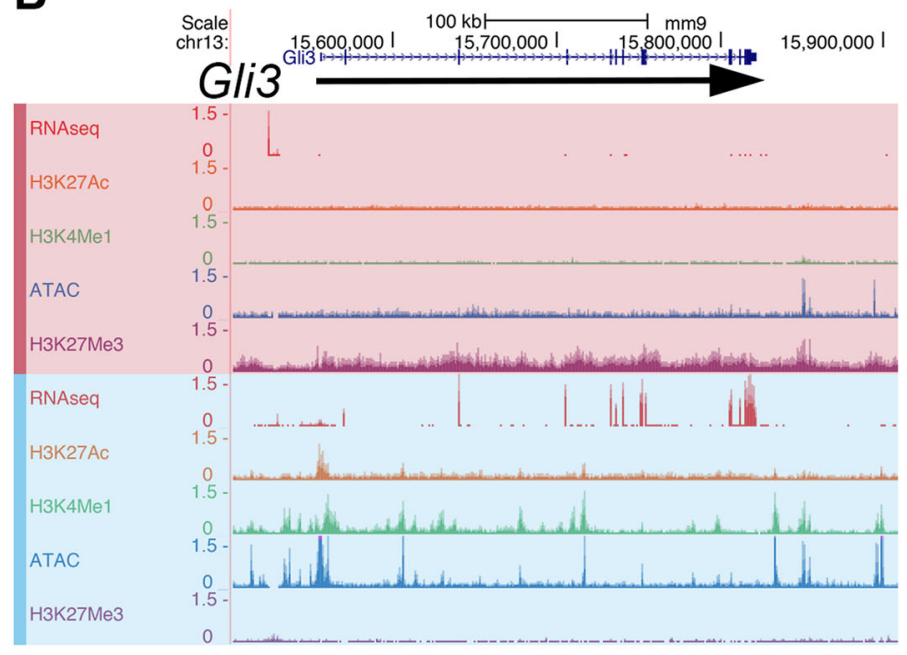

C

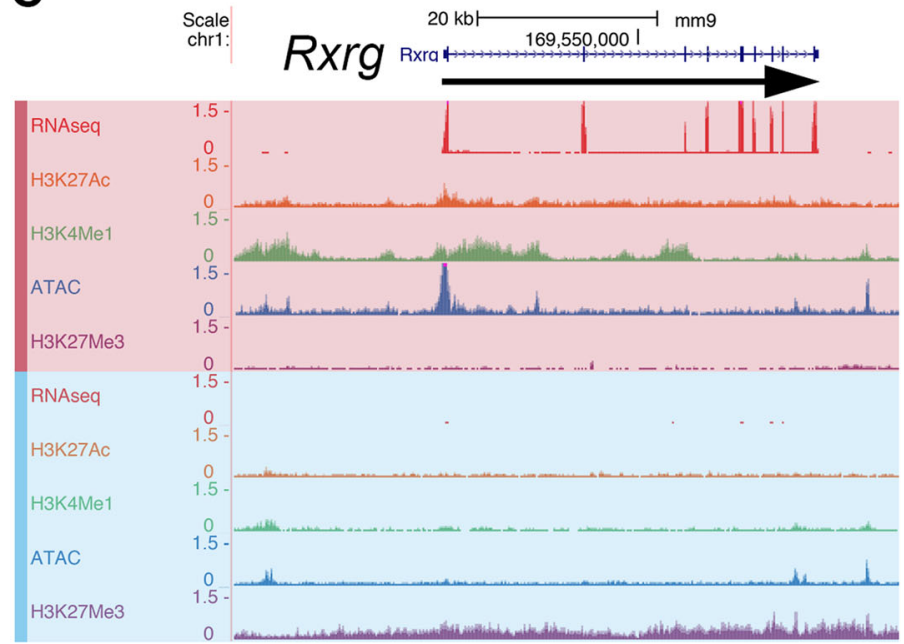

Fig. 2 (See legend on next page.) 
(See figure on previous page.)

Fig. 2 Epigenomic marks and expression for three key transcription factors. a /s/1 encodes a key pituitary transcription factor that is expressed in both TaT1 (red) and GHF-T1 (blue) cell lines. Data from RNA-Seq, CUT\&RUN for active chromatin marks (H3K27Ac and H3K4Me1), open chromatin (ATACseq), and CUT\&RUN for repressive chromatin marks (H3K27Me3) is visualized for each cell line in genome browser tracks. $\mathbf{b}$ Gli3 is in active chromatin and expressed in GHF-T1 cells. Gli3 is not expressed in TaT1 cells, and the chromatin is inaccessible with repressive marks. c Rxrg is expressed and in active chromatin in TaT1 cells, while not expressed and bearing repressive marks in GHF-T1 cells. $N=2$ for histone marks/cell line

POU1F1 binding was detected at the Nrxn1 promoter in TaT1 cells relative to GHFT1 cells, and Nrxn1 expression increased from nearly zero in GHFT1 cells to 5 FPKM in TaT1 cells (Fig. 3c). Nrxn1 is critical for proper synapse formation, but the role in pituitary is unknown [52].

Genome-wide analysis of POU1F1 binding in both cell lines revealed that the majority of binding is in putative enhancers and associated with higher levels of gene expression. There are a significant number of unique POU1F1 binding sites in each cell line: only one third of all POU1F1 binding sites are shared between the two lines (Fig. 3d). Only 15-16\% of POU1F1 binding sites in GHF-T1 cells $(10,980$ out of 69,644$)$ and ToT1 cells $(9360$ out of 63,036$)$ are within $1 \mathrm{~kb}$ of a transcription start site (TSS), suggesting most POU1F1 binding is at enhancers. Consistent with this, nearly $70 \%$ of genes whose promoters are bound by POU1F1 in the differentiated line are also bound by POU1F1 in the precursor line (Fig. 3e). We found that POU1F1 binding is associated with higher levels of gene expression in both cell lines (Fig. 3f).
A

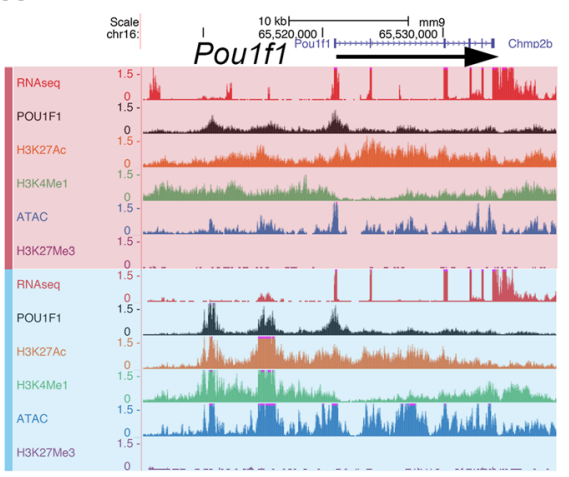

B

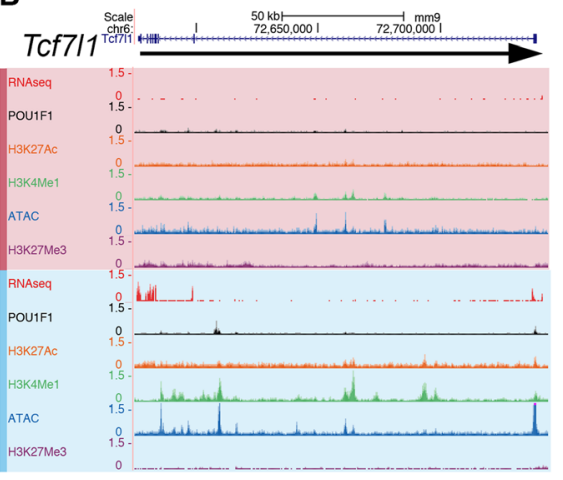

C

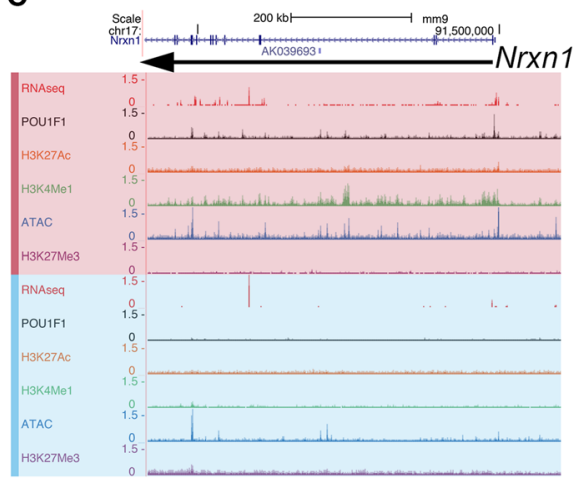

D
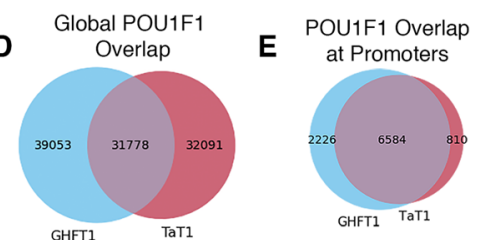

at Promoters$$
F
$$

$\mathbf{F}$

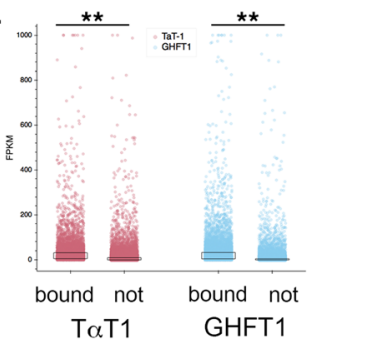

Fig. 3 Comparison of POU1F1 binding sites in GHFT1 and TaT1 cells. a Poulf1 is expressed in both cell lines, contains active chromatin marks, and exhibits similar POU1F1 binding to enhancer elements. Data from RNA-seq, CUT\&RUN for POU1F1 and active chromatin marks (H3K27Ac, H3K4Me1), ATAC-seq, and CUT\&RUN for repressive marks (H3K27Me3) is visualized in genome browser tracks for TaT1 cells (red) and GHF-T1 (blue). b Tcf7/1 is an example of a gene uniquely bound by POU1F1 and expressed in GHF-T1 cells. c Nrxn1 is an example of a gene uniquely bound by POU1F1 and expressed in TaT1 cells. $\mathbf{d}$ A Venn diagram illustrating the number of shared and distinct POU1F1 binding sites throughout the genomes of GHF-T1 and TaT1 cells. e A Venn diagram showing the number of shared and distinct genes whose promoters and regulatory elements are bound by POU1F1 in GHF-T1 and TaT1 cells. $\mathbf{f}$ Scatter plot showing the FPKM of genes whose promoters are bound or not bound by POU1F1 in both TaT1 and GHF-T1 cells. In both TaT1 and GHF-T1 cells, genes whose promoters are bound by POU1F1 are more highly expressed. The boxed regions represent the middle quartiles, i.e., $25-75 \%$. The significance is represented by asterisks ( $p$ values $4 \times 10^{-114}$ and $8 \times 10^{-130}$, respectively). $N=1$ for POU1F1/cell line 
POU1F1 binding is associated with higher ATAC-seq signals in GHF-T1 cells than in T $\alpha \mathrm{T} 1$ cells (Fig. 4a). As expected, sites of POU1F1 binding specific to T $\alpha \mathrm{T} 1$ cells

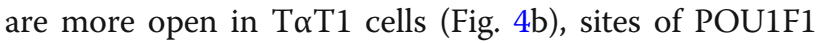
binding specific to GHF-T1 cells are more open in GHF-T1 cells (Fig. 4c), and shared POU1F1 sites have similar signatures of open chromatin in both cell lines (Fig. 4d).

Active enhancers (states containing both H3K27Ac and H3KMe1 in ChromHMM) are heavily enriched for POU1F1 binding in both cell lines (Fig. 4e, f). GHF-T1 enhancers appear to have greater POU1F1 binding than do T $\alpha \mathrm{T} 1$ enhancers. POU1F1 binding that is specific to ToT1 cells is associated with active chromatin states in T $\alpha$ T1, but it is less so in GHF-T1 cells (Fig. 4g). Similarly, GHF-T1-specific POU1F1 binding is broadly associated with active chromatin states in GHF-T1 cells, but it less so in T $\alpha \mathrm{T} 1$ cells. Sites bound by POU1F1 in both cell types have similarly active chromatin states, as expected.

To identify transcription factors that may be associated with differential POU1F1 binding between the cell lines,
A

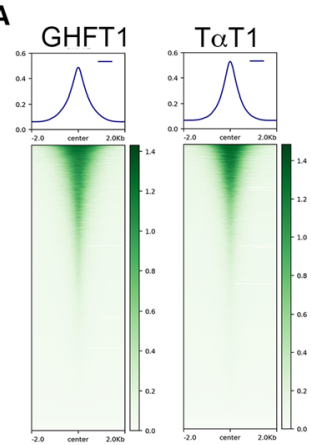

E

H3K4Me1 H3K27Ac POU1F1 H2K27Me3
B

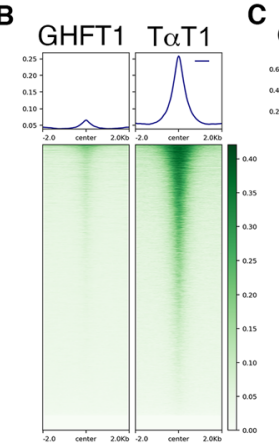

$\mathbf{F}$

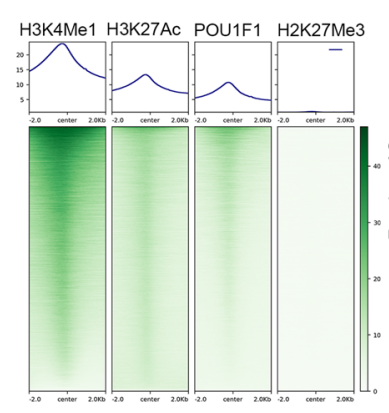

J POU - Homeodomain ATCCATAATTCA

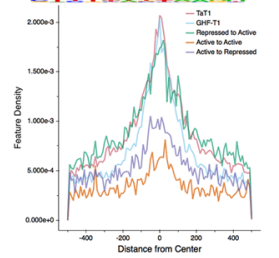
bZIP

I

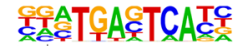

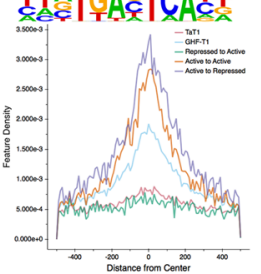

Helix-T

c

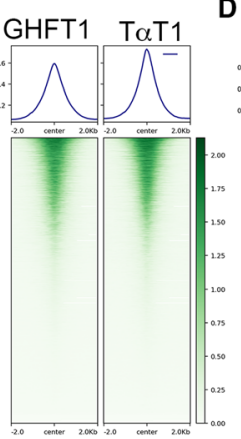

D

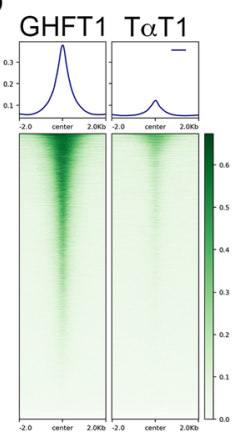

$\mathbf{G}_{1}$

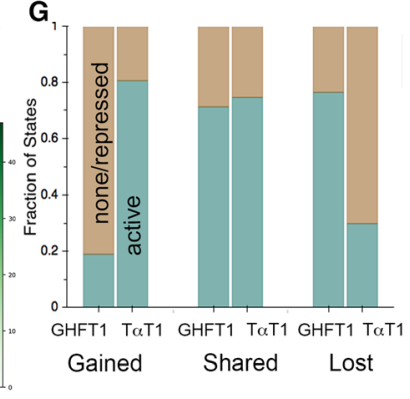

K Basic Helix-Loop-Helix 둔.TTGCCATGCCAA
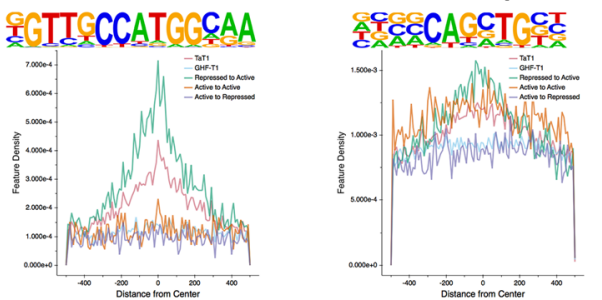

Fig. 4 Comparison of open chromatin between GHF-T1 and TaT1 cells and prediction of transcription factor binding. a ATAC-seq signal at POU1F1 binding sites in GHFT1 and TaT1 cells. b ATAC-seq signal at POU1F1 binding sites that are specific to TaT1 cells. c ATAC-seq signal at POU1F1 binding sites that are shared between Ta T1 and GHF-T1 cells. d ATAC-seq signal at POU1F1 binding sites that are specific to GHF-T1 cells. e POU1F1 signal at enhancers in GHFT1 cells. $\mathbf{f}$ POU1F1 signal at enhancers in TaT1 cells. $\mathbf{g}$ The composition of active (teal) chromatin states vs repressed or unmarked chromatin states (brown) for POU1F1 binding sites in GHF-T1 and TaT1 cells is compared. Active states are defined as states 1-6 (Supplemental Figure 5). TaT1-specific sites (gained in differentiation, left) are mostly active in TaT1 cells, while shared sites (center) have equivalent active states. GHF-T1-specific sites (lost in differentiation, right) are mostly active in GHFT1 cells. $\mathbf{h}$ Density of POU1F1 motifs across POU1F1 binding sites in GHF-T1 cells (blue), TaT1 cells (red), at TaT1-specific POU1F1 binding sites that are repressed in GHF-T1 cells and active in TaT1 cells (repressed to active, green), POU1F1 binding sites that are shared in GHF-T1 and TaT1 cells that are active in both (active to active, orange), and POU1F1 binding sites that are specific to GHF-T1, and are in an active state in GHF-T1 cells and a repressed state in TaT1 cells (active to repressed, purple). i Similar analysis as $\mathbf{h}$, for the bZIP transcription factor sites, like FRA1. $\mathbf{j}$ Similar analysis as $\mathbf{h}$, for the HTH transcription factor sites, like RFX1. k Similar analysis as $\mathbf{h}$, for bHLH transcription factor sites, like ASCL1. Supplemental Figure 6 shows more motifs 
we analyzed the chromatin states associated with shared and unique POU1F1 binding sites and screened these for binding motifs. We classified genomic sites that had POU1F1 binding exclusively in T $\alpha \mathrm{T} 1$ cells, were in active states in the T $\alpha \mathrm{T} 1$ cells, and were in repressed states in GHF-T1 cells (repressed to active), POU1F1 binding sites that are shared between GHF-T1 and T $\alpha \mathrm{T} 1$ and are in similarly active chromatin in both (Active to Active), and GHF-T1-specific POU1F1 binding sites that are in active chromatin in GHF-T1 sites and are repressed in T $\alpha \mathrm{T} 1$ cells (labeled active to repressed). This revealed an expected enrichment in POU1F1 motif density at the center of POU1F1 sites in both GHF-T1 and TaT1 cells (Fig. 4h). There was a striking enrichment of bZIP motifs at the center of GHF-T1-associated POU1F1 binding sites (Fig. 4i), suggesting that bZIP factors influence POU1F1 binding in progenitors.

Interestingly, there was remarkable helix-turn-helix motif density at the center of T $\alpha \mathrm{T} 1$ POU1F1 binding sites, and even more so at repressed to active sites (Fig. 4j). Similarly, there was increased bHLH motif density at repressed to active sites (Fig. 4k). These data suggest that HTH and bHLH factors mediate POU1F1 binding to novel sites in thyrotropes.

\section{Stretch enhancers}

Twenty-four percent of the putative enhancers that we identified were in open chromatin in both the precursor and differentiated cell lines, as defined by at least $25 \%$ bidirectional overlap (Fig. 5a). There were 15\% more areas of open chromatin at putative enhancers in the differentiated, thyrotrope state than the precursor state. The distribution of enhancer sizes was very similar between the two cell lines (Fig. 5b). Enhancers larger than $3 \mathrm{~kb}$ in length, called stretch enhancers, represent $5-10 \%$ of all enhancers, are typically cell-type specific and often enriched in disease-associated areas [53, 54]. Stretch enhancers represent $4.9 \%$ of the enhancer population in the precursor cell lineage and $7.1 \%$ of the enhancer population in the differentiated thyrotrope population. This is within the expected fraction, and the increased abundance in T $\alpha \mathrm{T} 1$ cells is consistent with their more differentiated state. While GHF-T1 and T $\alpha \mathrm{T} 1$ cells share $24 \%$ of all enhancers, only $10 \%$ of stretch enhancers are shared between the two cell types (Fig. 5a).

We compared the expression of the closest gene to each stretch enhancer and found that expression was highly cell-type specific. Genes closest to precursor stretch enhancers were more highly expressed in the precursor cell line, whereas the genes closest to thyrotrope stretch enhancers were expressed at higher levels in the thyrotrope cell line (Fig. 5c). Genes closest to shared stretch enhancers had similar gene expression in both cell lines.
We sought to determine whether genes associated with thyrotrope function in both mouse and human were closer to stretch enhancers. We generated a list of 25 candidate genes associated with thyrotrope differentiation and/or function (Supplemental Table 3), and we found that the TSSs of all of these genes were within $100 \mathrm{~kb}$ of $28 \mathrm{~T} \alpha \mathrm{T} 1$ stretch enhancers and only 6 GHFT1 stretch enhancers (Fig. 5d). To determine whether this result was significant, we randomly selected 25 genes 10,000 times, ensuring the genes had similar expression levels, and we counted the number of stretch enhancers within $100 \mathrm{~kb}$ of the transcription start site of those randomly selected genes. The randomly selected genes were within $100 \mathrm{~kb}$ of $28 \mathrm{~T} \alpha \mathrm{T} 1$ stretch enhancers only two times out of 10,000 , yielding an empirical $p$ value of 0.0002 , which confirms the enrichment of T $\alpha \mathrm{T} 1$ stretch enhancers at thyrotrope-signature genes.

To probe the potential value of these data for application to human disease studies, we mapped the mouse enhancers in T $\alpha \mathrm{T} 1$ and GHF-T1 cells from the $\mathrm{mm} 9$ genome onto the human genome, hg19. Because 90\% of GWAS SNPs are intronic or intergenic, and stretch enhancers are heavily enriched for disease SNPs, we expected to implicate thyrotropes in disease phenotypes by uncovering enrichment of disease SNPs in T $\alpha \mathrm{T} 1$ stretch enhancers $[4,53]$. We used GARFIELD to measure the enrichment of these SNPs in GHF-T1 and TaT1 and stretch enhancers, while accounting for linkage disequilibrium, minor allele frequency, and distance to TSS [55]. We compared their enrichment to stretch enhancers found in heterologous cell lines including but not limited to Islet cells, GM12878 (human Blymphocyte cells), and K562 (human myelogenous leukemia cells) cells [53]. Supplemental Figure 7 shows the enrichment odds ratios for all GWAS studies and cell line stretch enhancers, as well as their $p$ values. The study that exhibited the greatest enrichment of SNPs in T $\alpha$ T1 stretch enhancers (odds ratio of 4.7) was from GWAS done on the neuroticism sub-phenotype of feeling miserable [56]. While the significance of this is uncertain, untreated hypothyroidism can be associated with fatigue and depression.

\section{In vitro validation of enhancers}

We sought to test putative enhancers of a sampling of thyrotrope-signature genes, namely Gata2, Cga, and Pitx1, by transient transfection of T $\alpha \mathrm{T} 1$ cells. We identified putative regulatory elements as regions with significantly enriched ATAC-seq signals near these genes. The promoter-proximal sequences of each gene were amplified from genomic DNA and fused to a luciferase reporter gene. Putative regulatory elements were amplified from genomic DNA and cloned in both the forward and reverse orientation upstream of the promoter-proximal 
A

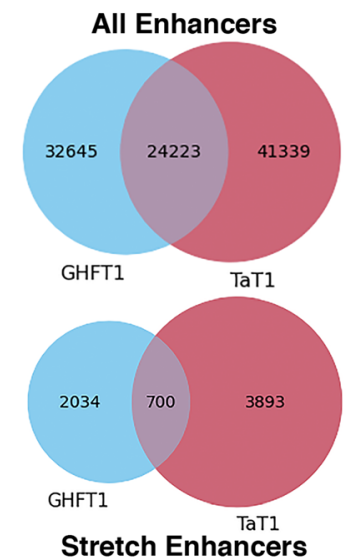

C

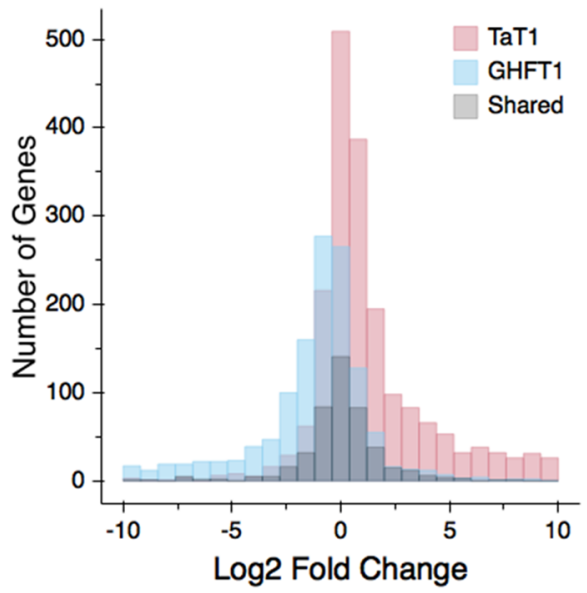

B
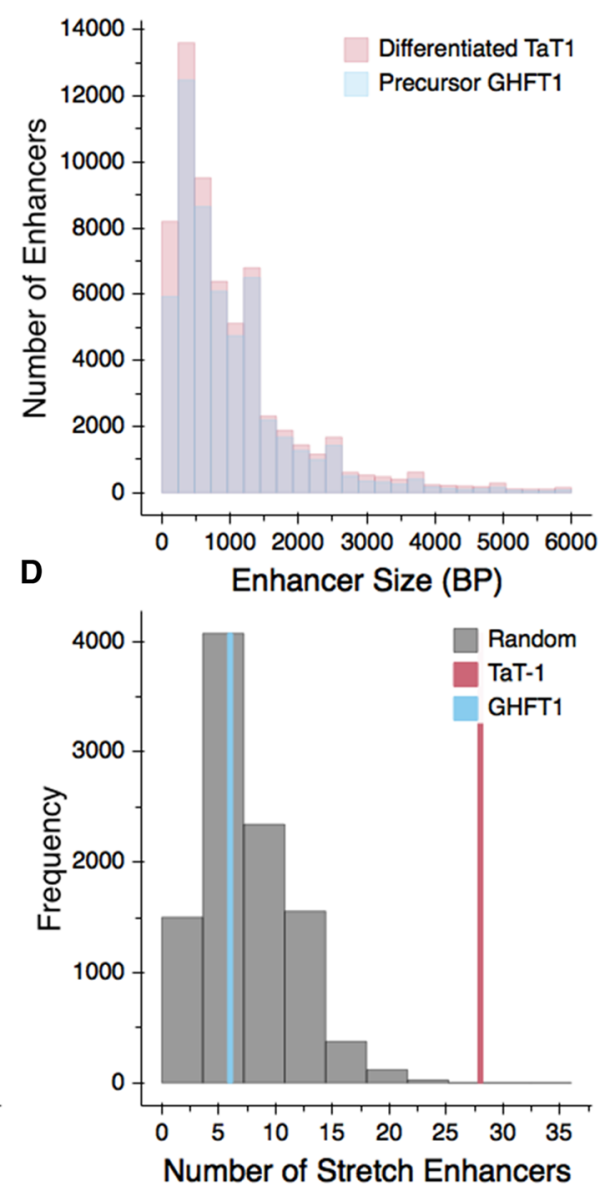

Fig. 5 Comparison of putative enhancers in GHF-T1 and TaT1 cells. a A Venn diagram showing the number of shared and distinct enhancers in GHF-T1 and TaT1 cells (top). A Venn diagram showing the number of shared and distinct stretch enhancers in GHF-T1 and TaT1 cells (bottom). b A histogram showing the distribution of enhancer sizes in GHF-T1 (in blue) and TaT1 cells (in red). c A histogram showing the log 2-fold-change in expression of the genes that are closest to GHF-T1-specific stretch enhancers (blue), TaT1-specific stretch enhancers (red), and shared stretch enhancers (black). d Number of TaT1 (red) and GHF-T1 (blue) stretch enhancers within $100 \mathrm{~kb}$ (50 kb upstream or downstream) of the TSS of 25 genes important for thyrotrope function (Supplemental Table 3). To evaluate the significance of the difference, 25 genes were randomly selected, normalized for gene expression, and assessed for stretch enhancers. This process was repeated in 10,000 iterations and displayed as a histogram (gray)

region. The transfection efficiency of T $\alpha \mathrm{T} 1$ cells is low $(\sim 20 \%)$, and the results vary, likely due to poor adherence of cells to the plate. Thus, all experiments were performed with six replicates. We detected strong enhancer elements for Gata2 and Pitx1 (Fig. 6). The position (genome coordinates) of cloned promoters and elements is presented in Supplemental Table 4.

Gata2 is implicated in Tshb transcription and proper thyrotrope function $[13,18,21]$. Gata 2 has two promoters located upstream of a noncoding exon [57]. The more distal promoter is located $\sim 5 \mathrm{~kb}$ upstream of the more proximal promoter, and it drives expression in Sca-1+/c-kit+ hematopoietic progenitor cells, while the downstream promoter drives Gata2 expression in most other tissues. The RNA-seq data revealed that the downstream promoter is the only one utilized in TaT1 and
GHF-T1 cells. Gata2 expression is five-fold higher in T $\alpha \mathrm{T} 1$ cells than in GHF-T1 cells and there is a larger area of accessible chromatin upstream of Gata2 in the T $\alpha \mathrm{T} 1$ cells $(\sim 2.8 \mathrm{~kb}$ vs $0.9 \mathrm{~kb}$, Fig. $6 \mathrm{a})$. There is no difference in activity between the $0.2 \mathrm{~kb}$ and $0.9 \mathrm{~kb}$ promoter-proximal region in T $\alpha \mathrm{T} 1$ cells, but the larger, $2.8 \mathrm{~kb}$ promoter-proximal region of Gata2 stimulated luciferase activity 5 -fold $(p$ value $=0.009$ ). This indicates the presence of enhancer elements between 0.9 and 2.8 $\mathrm{kb}$ of the common TSS for Gata2. We tested three distal elements, fusing them with the smallest, $0.2 \mathrm{~kb}$ Gata2 promoter construct. An element $\sim 100 \mathrm{~kb} \mathrm{3'}$ ' of the common Gata2 promoter had significant POU1F1 binding and drove the highest levels of luciferase expression (3fold increase, $p$ value $=0.005$ ). Thus, we identified two enhancer elements for Gata2 expression in thyrotropes, 
A

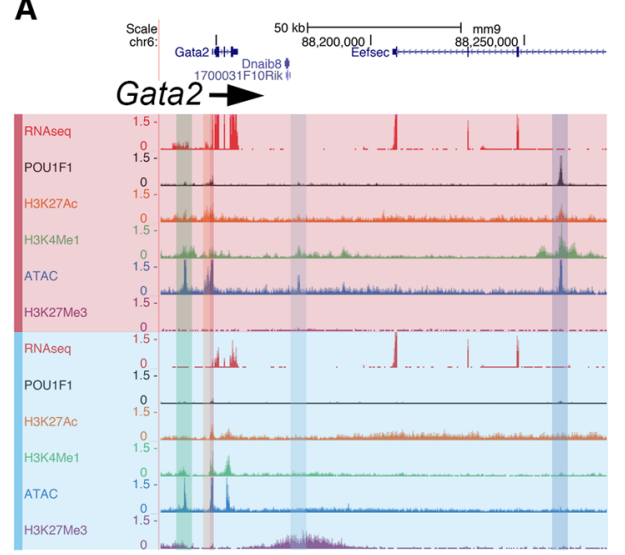

C

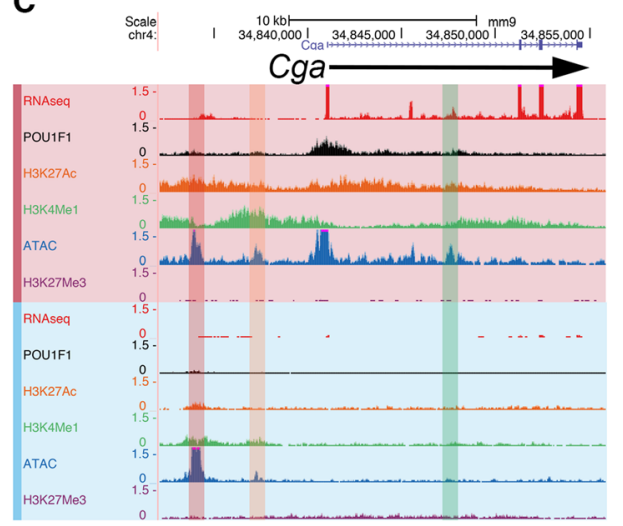

E

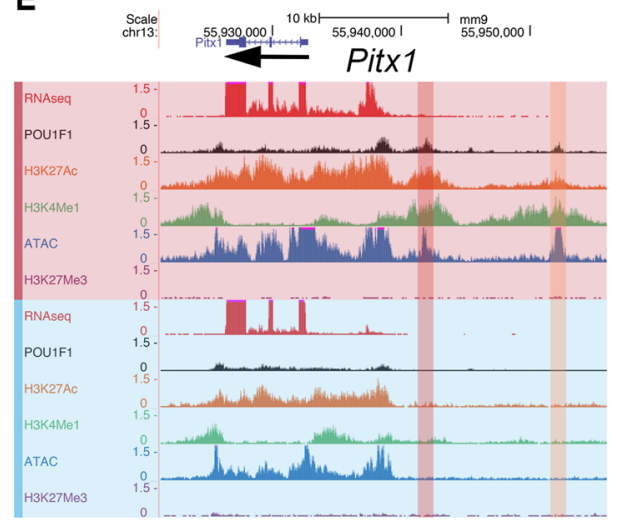

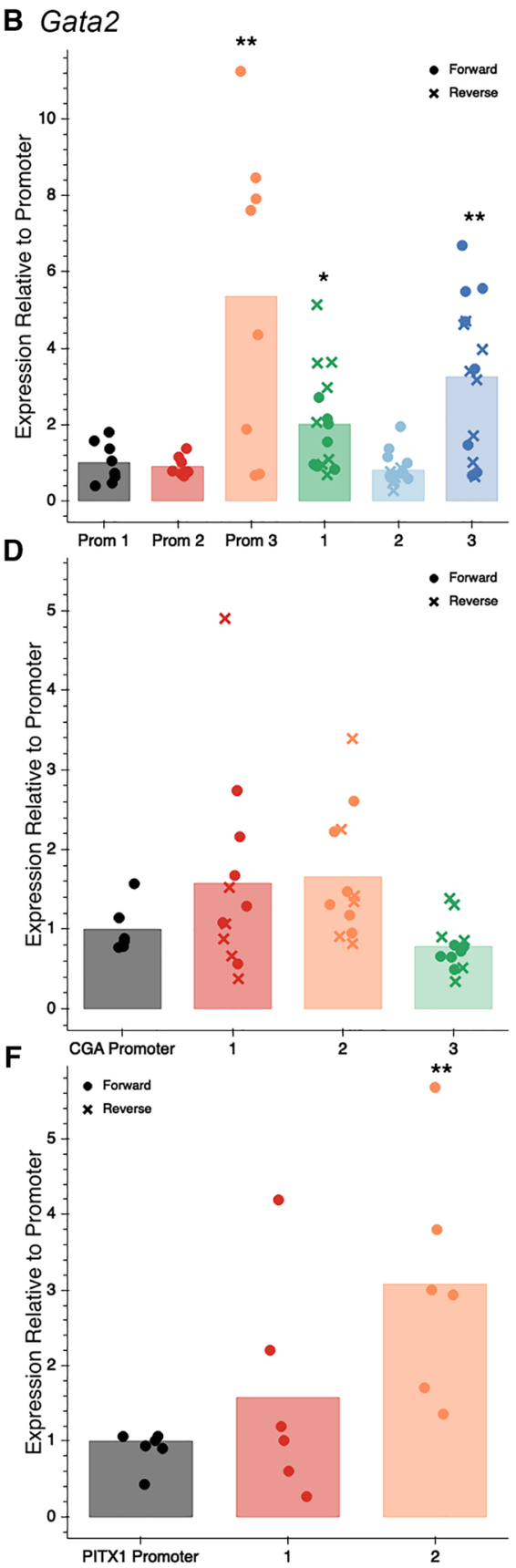

Fig. 6 Functional testing of putative enhancers by transient transfection. a Tracks for RNA-seq, POU1F1, H3K27Ac, H3K4Me1, ATAC-seq, and H3K27Me3 are shown for Gata2 in TaT1 (red) and GHF-T1 (blue) cells. The putative enhancer regions cloned for the luciferase assay are highlighted in red, orange, green, light blue, and dark blue. $\mathbf{b}$ The level of luciferase activity of each element relative to the smallest promoter region is shown. Prom 1, 2, and 3 represent the Gata2 promoter with $0.2,0.9$, and $2.8 \mathrm{~kb}$ of 5 ' flanking region, respectively. 1, 2, and 3 represent the three similarly highlighted elements in a tested in both the forward (circles) and reverse ( $x$ 's) orientation upstream of the $0.2 \mathrm{~kb}$ Gata2 promoter. The significance was evaluated with a two-sided $t$-test and indicated with asterisks where $p$ value $<0.05={ }^{*}$ and $p$ value $<0.01={ }^{*}$. c Same tracks as in $\mathbf{a}$, at the Cga locus, where elements tested are highlighted. $\mathbf{d}$ Level of luciferase activity of each element, color-coordinated with the highlighted elements in $\mathbf{c}$ in both the forward (circles) and reverse ( $x^{\prime}$ s) orientation. e Same tracks as in $\mathbf{a}$ at the Pitx 1 locus, where elements tested are highlighted. $\mathbf{f}$ Level of luciferase activity of each element, color-coordinated with the highlighted elements in $\mathbf{f}$. Elements were tested only in the forward orientation. $N=6$ replicates/reporter gene

one in the proximal promoter region, within $2.8 \mathrm{~kb}$ of the TSS, and a more distal one, approximately $110 \mathrm{~kb}$ downstream.
Cga is the alpha-subunit of TSH, and the gonadotropins, FSH and $\mathrm{LH}$, and it is expressed in both thyrotropes and gonadotropes. We tested three Cga enhancer 
elements, and two appeared to have some activity, although they did not reach statistical significance. The element $\sim 7 \mathrm{~kb}$ upstream of $C g a$ increased luciferase activity 1.5 -fold, and it has not been previously described. The element located $4.6 \mathrm{~kb}$ upstream of the Cga gene increased luciferase activity 1.6-fold and approached statistical significance $(p$ value $=0.07)$. This element is sufficient for developmental activation, cell type-specific expression, and hormonal regulation in transgenic mice (Fig. 6b) $[16,58,59]$.

Pitx1 has a role in Pomc expression and hindlimb formation in mice and humans [60,61]. Pitx 1 and the related Pitx 2 gene drive early pituitary development and are expressed in thyrotropes and gonadotropes [24]. Mice with a pituitary-specific disruption of Pitx2 exhibit elevated Pitx1 expression in response to induced hypothyroidism, suggesting functional compensation [22]. The Pitx 1 regulatory landscape extends over $400 \mathrm{~kb}$ and includes a pituitary enhancer $110 \mathrm{~kb}$ upstream [62]. ATAC-seq signatures revealed two previously undescribed thyrotrope-specific regions of open chromatin 9 and $19 \mathrm{~kb}$ upstream of the Pitx 1 transcription start site (Fig. 6c). The proximal element did not have statistically significant enhancer activity. The distal element, however, increased luciferase activity 3 -fold $(p$ value $=0.009$ ) .

\section{Discovery of a novel TSH $\beta$-subunit enhancer}

A bacterial artificial chromosome clone containing $T s h b$ and $150 \mathrm{~kb}$ of surrounding DNA sequence was sufficient to drive expression in thyrotropes of transgenic mice [22], but there is no information about the location of key regulatory elements within this region. In fact, multiple efforts to drive expression in transgenic mice with smaller constructs were unsuccessful [63]. We sought to leverage the information we have about the chromatin states in the T $\alpha \mathrm{T} 1$ cells to identify elements sufficient for Tshb expression in mice. Knowing that the $150 \mathrm{~kb}$ BAC was sufficient to drive expression in thyrotropes, we limited our search to this region and found five areas with high ATAC-seq signal in T $\alpha \mathrm{T} 1$ cells (Fig. 7a). We tested each of these elements both in the forward and reverse orientation fused to a $438 \mathrm{bp} T s h b$ promoterproximal region driving luciferase expression (Fig. $7 \mathrm{~b}$, genomic coordinates of the cloned promoter and putative enhancer elements are in Supplemental Table 4). We discovered that a $1.4 \mathrm{~kb}$ element located $7.7-6.6 \mathrm{~kb}$ upstream of the Tshb transcription start site drove significant levels of luciferase (hereafter named element 4). Element 4 had extensive ATAC-seq signal and H3K4Me1 and POU1F1 binding, consistent with the observation that POU1F1 is important for Tshb expression. We tested the ability of GATA2 and POU1F1 to activate $T s h b$ promoter alone and in conjunction with element 4 in heterologous CV1 cells. GATA2 and POU1F1 independently cause modest increases in Tshb-luc reporter gene expression (2.7-fold and 1.6-fold respectively), and together they drive higher expression (5-fold, Fig. 7c), similar to previous reports [13]. In the presence of element 4, POU1F1 has very modest effects on reporter gene expression (1.3-fold increase), but GATA2 has a strong effect (4.3-fold increase). GATA2 and POU1F1 do not have an obvious additive effect on element 4 reporter activity (4.4-fold increase) in contrast to the promoter-proximal region. This suggests that GATA2 is a powerful regulator of $T s h b$ expression through interaction with element 4 . To determine which other factors may be binding Element 4, we checked for the presence of over 1000 Jaspar motifs within element 4 at an $80 \%$ threshold. We found extensive predicted GATA2 and PITX1 binding (Fig. 7d). A more complete list of predicted binding factors is presented in Supplemental Table 5.

We tested whether element 4 was sufficient to drive expression in transgenic mice by placing it in front of the Tshb promoter and a YFP reporter gene. This construct was injected into fertilized eggs that were subsequently transferred to pseudopregnant foster mothers. We dissected the pituitaries of eleven founder transgenic mice at 4 weeks of age and examined the expression of YFP using immunohistochemistry (Fig. 7e, f). Forty-five percent $(5 / 11)$ exhibited transgene expression in the pituitary gland: three founders had low levels of YFP expression, and two founder mice had higher levels of YFP activity. This contrasts with our previous transgenic analyses using $-1.1 \mathrm{~kb}$ to $+620 \mathrm{bp}$ of Tshb that yielded no expression ( $0 / 3$ lines), and a larger construct containing $-6 \mathrm{~kb}$ to $+43 \mathrm{bp}$ that yielded no expression (0/4 lines), even after 10 days of treatment with propothiouracil, which would be expected to increase Tshb transcription at least ten-fold [63]. We quantified expression in two element 4 transgenics. $87 \%$ of YFP-positive cells $(N=63$ / 76) were also positive for TSH in founder 399, indicating high specificity for thyrotropes, and $6 \%$ of the transgenic thyrotropes were also positive for YFP (63/872), signifying low penetrance of expression. In total, $31 \%$ of YFPpositive cells $(8 / 26)$ were positive for TSH in founder 423 , and $3 \%$ of the transgenic thyrotropes were also positive for YFP $(8 / 270)$. This suggests that element 4 contributes to $T s h b$ expression, although other elements are required for higher penetrance expression. This serves as a proof of the principle that combined transcriptome and epigenome data can be valuable for identifying enhancer elements that function in developmentally specific cell lines and intact animals.

\section{Discussion}

Our work builds on the ENCODE effort to discover regulatory elements in diverse tissues. This represents 

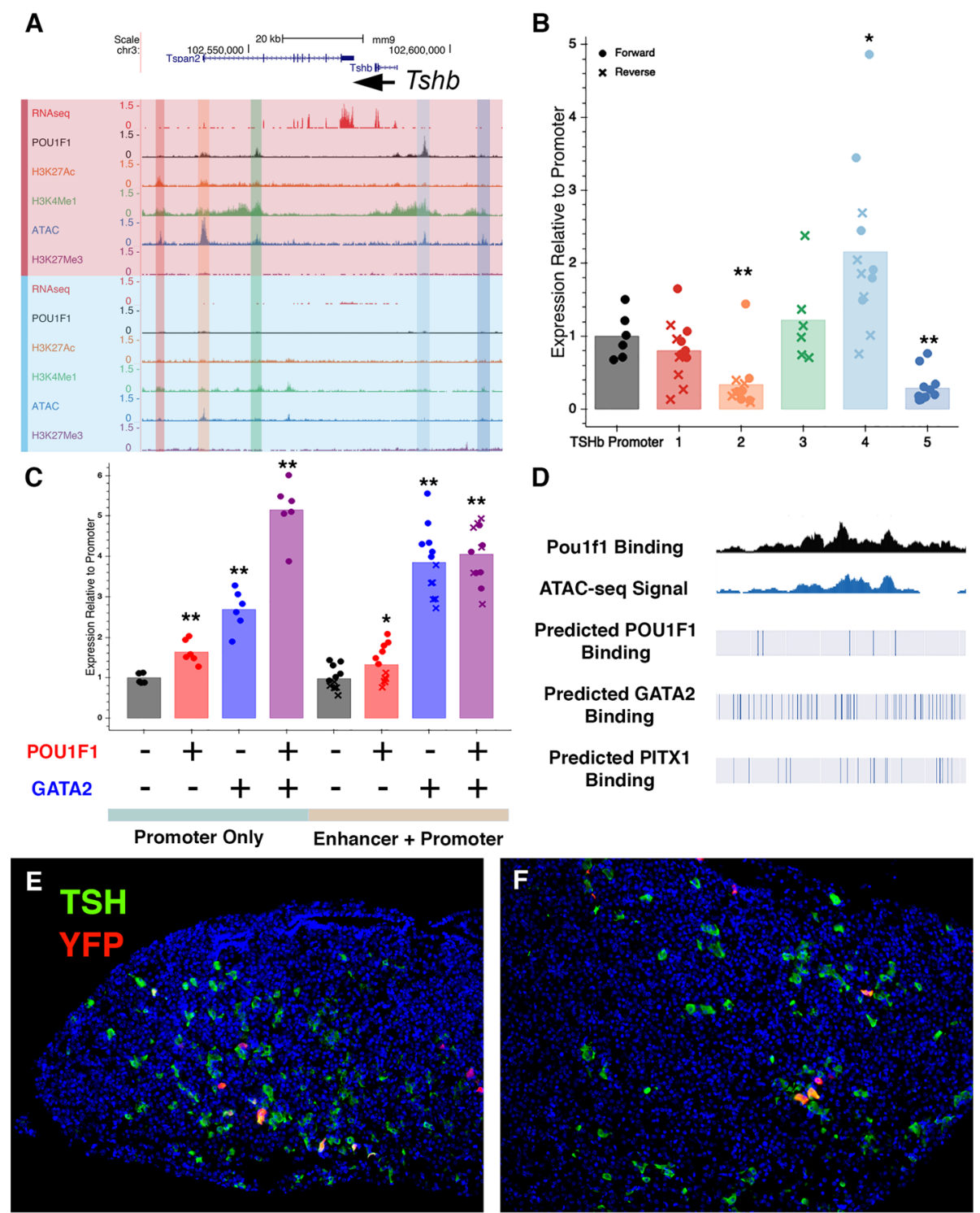

Fig. 7 Evaluation of Tshb regulatory elements in transfection and transgenic mice. a Tracks illustrating the results of RNA-seq, CUT\&RUN for POU1F1, H3K27Ac, and H3K4Me1, ATAC-seq, and CUT\&RUN for H3K27Me3 are shown for the Tshb locus in TaT1 cells (red) and GHF-T1 cells (blue). Elements that were tested functionally are highlighted. The significance is indicated with asterisks: $p$ value $<0.05=* ; p$ value $<0.01={ }^{* *}$. b TaT1 cells were transfected with a $438 \mathrm{bp}$ Tshb promoter-proximal element fused to luciferase and putative regulatory elements in the forward (filled circles) or reverse $(x)$ orientation. Luciferase activity for each construct is normalized to the promoter-only luciferase activity and significant differences from promoter alone are indicated with asterisks $\left(p<0.05={ }^{*}\right.$ and $\left.p<0.01={ }^{*}\right)$. c Heterologous CV1 cells were transfected with the Tshb promoter-only construct or the promoter plus element 4 construct, along with expression vectors for POU1F1 and/or GATA2 as indicated by + or - . Significant differences from the reporter gene alone are indicated with asterisks $\left(p<0.05 *^{*}\right.$ and $\left.p<0.01=^{* *}\right)$. The values obtained for both constructs with POU1F1 or GATA2 expression vectors were significantly different, $p<0.01$. $\mathbf{d}$ Genome browser track illustrating element 4 (1.4 kb located 6.6-7.7 kb upstream of the Tshb transcription start site) with experimentally determined sites for POU1F1 binding and ATAC-seq, and predicted binding sites for POU1F1, GATA2, and PITX1 that reach a confidence level of at least 0.8 in JASPAR. An extended list of binding motifs predicted in Element 4 is presented is in Supplemental Table 5. e A section of the pituitary gland from transgenic founder 399 was co-immunostaining for YFP (red) and TSHB (green), revealing overlap in expression (yellow). Nuclei are stained with DAPI (blue). f Same as e, in founder mouse 423. For transfections, $N=6 /$ reporter gene

the first systematic characterization of the epigenome and transcriptome of a thyrotrope-like cell line, providing insight into the changes that are associated with the differentiation of committed POU1F1 pituitary cells into thyrotropes. POU1F1 has a similar binding profile at promoters in the two cell lines, but there are novel binding sites at enhancers in each cell line that are associated with striking shifts in chromatin states. Global analysis of positive histone marks (H3K27Ac and H3K4Me1) revealed putative active enhancers in the two cell lines. 
We demonstrated that many of the enhancers surrounding thyrotrope-signature genes drive expression in a thyrotrope cell line. Furthermore, an enhancer element upstream of $T s h b$ was sufficient to drive expression in some thyrotropes in transgenic mice. The transcriptomic, epigenomic, and POU1F1 binding data here contributes significantly to our understanding of thyrotrope cell specification, which are the key cells for regulation of thyroid gland development and growth and metabolism.

This is the first deep expression profiling reported for GHF-T1 and T $\alpha \mathrm{T} 1$ cells. The T $\alpha \mathrm{T} 1$ cells have been used extensively as a thyrotrope-like cell to study the molecular mechanisms of hypothalamic input and thyroid hormone feedback on Tshb expression, and remarkably, they also respond to retinoids and secrete TSH in response to diurnal cues [28-30]. In total, $92 \%$ of the genes we predicted would be expressed in a thyrotrope-like cell were detected in T $\alpha \mathrm{T} 1$ cells at $>1$ FPKM (Supplemental Table 3). Recent single-cell gene expression studies of pituitary glands from adult rodents and developing human fetuses have revealed expected and novel genes enriched in thyrotropes, including Tshb, Trhr, Dio2, Pcsk2, Dpp10, Sox11, Nrg4, and others [64-66]. The majority $(77 \%, N=35)$ of thyrotrope-enriched genes identified by single-cell sequencing were expressed at levels $>1$ FPKM in T $\alpha$ T1 cells, and $96 \%$ of those genes exhibited elevated expression in T $\alpha \mathrm{T} 1$ cells relative to GHFT1 $(N=27)$ (Supplemental Figure 9, Supplemental Table 6). Thus, the gene expression data confirm the strong relationship between TaT1 cells and thyrotropes in vivo.

As hormone-producing cells mature, they ramp up translational machinery for robust hormone production, and CREB3L2 is a master regulator of this process in the pituitary corticotropes [67]. While Creb3l2 is not highly expressed in T $\alpha \mathrm{T} 1$ cells, Creb3l1 is expressed nearly 30fold higher in ToT1 cells than in GHF-T1 cells (172.5 FPKM vs. 5.9 FPKM). It is possible thyrotropes use a similar mechanism of increasing translation to meet the demand for thyrotropin. Consistent with this, Creb3l1 is upregulated in a model of thyrotrope adenoma [68].

Pituitary endocrine cells are electrically excitable, and voltage-gated calcium influx is the major trigger for hormone secretion [37]. G protein-coupled receptors, ion channels, and hormones all are considered components of cellular identity. For example, thyrotropes have unique electrical activity relative to other pituitary

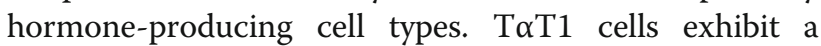
bursting pattern of action potentials that are affected by exposure to TRH and thyroid hormone, but the nature of the ion channels regulating TSH secretion is not understood $[69,70]$. The involvement of ion channels in excitation-secretion coupling is an area of active study. The hypothalamic factors $\mathrm{CRH}, \mathrm{TRH}, \mathrm{GHRH}$, and somatostatin have an effect on electrical activity in corticotropes, lactotropes, and somatotropes. Thyrotropes have not been well-studied in this regard. Our study provides evidence for the acquisition of ion channel gene expression as progenitors adopt the thyrotrope fate. Voltage-gated potassium channels Kcnc3, Kcnq2, Kcnk1, and $K c n k 2$ were highly expressed in T $\alpha \mathrm{T} 1$ cells. Interestingly, KCNQ1 missense mutations cause growth hormone deficiency [71]. We also found that sodium channel genes are more highly expressed in two cell types that express hormones, Pit1-triple and ToT1, than in lines that do not express hormones. The calcium channel CACNA1G, a low-voltage activated, T-type channel, was highly elevated in T $\alpha \mathrm{T} 1$ cells. These observations suggest that ion channel expression may be acquired as cells begin to differentiate. Additional studies may be necessary to determine whether they are pruned during maturation [37]. Knowing which ion channels are expressed in thyrotrope cells is the first step in understanding the mechanism whereby TRH stimulates TSH release in a pulsatile manner and according to the appropriate diurnal rhythm.

Several transcription factors had higher levels of expression in ToT1 cells relative to GHFT1, including ISL1, RXRG, and LHX3. Increased expression of Isl1 and $R x r g$ was expected because pituitary-specific deletion of Isl1 causes reduced thyrotrope differentiation [19], and several lines of evidence support a role for Rxrg. RXRG suppresses serum TSH levels and Tshb transcription, Rxrg-deficient mice have central resistance to thyroid hormone, and loss of retinoic acid signaling suppresses thyrotrope differentiation [46, 47]. Isl1 had extensive POU1F1 binding across the $1 \mathrm{MB}$ region surrounding it. $L h \times 3$ expression is detectable at e9.5 in the mouse pituitary placode and expression persists though adulthood [72]. Thus, we expected to detect $L h x 3$ transcripts in all pituitary cell lines. $L h x 3$ transcripts were nearly undetectable in Pit1-zero cells and in the precursor GHF-T1 lineage, but transcripts were higher in Pit1triple (1.6 FPKM) and highest in ToT1 cells (44.2 FPKM). Recently, an SV40-transformed pituitary precursor cell line was developed that expresses the stem cell marker SOX2 but not LHX3 [73]. There may be dynamic changes in $L h x 3$ expression during development that has not been documented.

SHH signaling is critical for establishing the pituitary placode and induction of $L h \times 3$ expression [34]. The GHFT1 precursor lineage expressed Gli2 and Gli3, which are downstream targets of $\mathrm{SHH}$, at higher levels than T $\alpha \mathrm{T} 1$ cells, suggestive of active SHH signaling. Gli2 and Gli3 promoters are associated with extensive H3K4Me1 and H3K27Ac, and active enhancers can be found upstream, downstream, and within their introns. By contrast, Gli2 and Gli3 have broad stretches of 
H3K27Me3 in the ToT1 line, a mark of active repression. The active expression of these elements in GHF-T1 cells underline how well these cell types represent the early pituitary state and suggest they could be for valuable for identifying GLI target genes that underlie pituitary developmental abnormalities [17].

POU1F1 is critical for development of thyrotropes, somatotropes, and lactotropes, and it likely interacts with other factors that specify the three different cell fates. Motif analysis near unique POU1F1 binding sites suggests which other factors may be involved. POU1F1 binding is associated with the homeodomain consensus binding motif, and sites of ToT1-specific POU1F1 binding that are repressed in GHF-T1 cells and active in TaT1 cells are heavily enriched for bHLH and HTH motifs. This raises the possibility that bHLH and HTH factors pioneer the binding of POU1F1 which then activates thyrotrope-specific expression.

Members of the RFX family of transcription factors are attractive candidates for interaction with POU1F1 to drive thyrotrope fate. These HTH factors contain DNA binding and heterodimerization domains and regulate cell fate in many organ systems, including the pancreatic islets and the sensory cells of the inner ear $[74,75]$. They interact with other POU and SIX factors to direct fate. Several members of the gene family are expressed in both GHF-T1 and T $\alpha$ T1 cells and in pituitary development between e12.5 and e14.5, a time when progenitors leave the cell cycle and initiate differentiation [76]. Future studies will be necessary to define the role of these genes in pituitary development.

The expression of bHLH factor genes Ascl1 (Mash1) and NeuroD4 (Math3) are elevated in ToT1 cells. However, thyrotrope commitment is normal in Ascl1 knockout and in triple knockout mice deficient in Ascl1, Neurod4, and Neurod1. These bHLH activating factors have overlapping functions in promoting somatotrope, gonadotrope, and corticotrope development [39, 40, 77, 78]. They promote pituitary stem cell exit from the cell cycle and act as selectors of cell fate, as triple knockout mice have more SOX2-positive cells and more lactotropes. bHLH factors play important roles in neuronal differentiation. For example, the BAM factors ASCL1, BRN2, and MYT1L are sufficient to transdifferentiate mouse embryonic fibroblasts (MEFs) into neurons. The Zn finger transcription factor MYT1L is highly upregulated in T $\alpha \mathrm{T} 1$ cells, and although the POU factor Brn2 is barely expressed in T $\alpha \mathrm{T} 1$ cells, POU1F1 is highly expressed. Thus, it is possible that ASCL1 acts in concert with MYT1L and POU1F1 to drive thyrotrope fate.

The top three most highly expressed bHLH factors in both of pituitary cell lines are the repressive bHLH factors in the ID family. The role of these genes in pituitary development has not been studied, but they may be important in regulating progenitor differentiation and cell fate selection. For example, a proper balance of activating and repressive bHLH factors is critical for cortical development [79]. Repressive ID and Hes factors are expressed in cortical progenitors, and induction of key activating bHLH factors drives these progenitors to differentiate. Astrocytes, however, require continued repressive bHLH factor expression. The interplay of active and repressive bHLH factors in pituitary development is likely complex.

\section{Conclusion}

This work represents the first thorough characterization of the epigenome and transcriptome in Poulf1 lineage progenitors and thyrotropes. We used this genome-wide catalog and tested enhancer function of elements in genes encoding thyrotropin, Cga and Tshb, the receptor for the hypothalamic releasing hormone that regulates thyrotropin, Trhr, and two crucial transcription factors, Gata2 and Pitx1. This provides proof of the principle that the catalog is valuable for dissecting gene regulation. In addition, we demonstrate that the Tshb enhancer element is sufficient for expression in thyrotropes in transgenic mice and is directly regulated by GATA2. We discovered that unique POU1F1 binding sites are associated with bZIP factor binding motifs in Poulf1 lineage progenitors and bHLH or bHTH binding motifs in thyrotropes. This suggests candidate gene families for regulating thyrotrope differentiation. Of the more than 30 known genes that are mutated in patients with hypopituitarism, 18 are transcription factors that regulate pituitary development and cell specification, indicating the clinical importance of this field of study [80]. The overwhelming majority of patients with hypopituitarism have no molecular diagnosis, suggesting additional genes remain to be discovered [17]. We provide a rich selection of candidate transcription factors that are differentially expressed in progenitors and thyrotropes. Amongst the top 40 of these, 9 are already implicated in pituitary development and disease. Future analysis of the remaining 31 candidates may uncover additional disease genes.

\section{Methods \\ Cell culture and transfection}

GHF-T1 and T $\alpha$ T1 cells were provided by Dr. Pamela Mellon at University of California San Diego and grown on uncoated 100-mm dishes and Matrigel-coated 60$\mathrm{mm}$ dishes, respectively. They were grown in DMEM (Gibco, 11995-065) with 10\% fetal bovine serum (Corning, 35016CV) and 1\% penicillin streptomycin (SigmaAldrich P4333). Cells were split 1:10 once they achieved $80 \%$ confluence. Six replicates of T $\alpha \mathrm{T} 1$ cells were transfected using FuGENE 6 with a 3:1 transfection reagent/ DNA ratio. Cells were collected $48 \mathrm{~h}$ post-transfection 
for collection and luciferase measurement was performed using Promega Dual-Glo (Promega \#E2920), and a GloMax 96 microplate luminometer.

Pit1-zero and Pit1-triple cells were developed by Dr. Stephen Liebhaber and grown as described [31].

\section{Cloning}

The DNA prepared for the plasmids used in the transfection experiments and transgenic mice was amplified from T $\alpha$ T1 DNA. Primers were designed to work with Phusion Green Hot Start II High-Fidelity PCR Master Mix (catalog \# F566S). Two methods were employed to clone plasmids containing the regulatory element, the respective promoter, and the YFP reporter. The first method involved adding 10-15 nucleotides onto the insert that overlapped with the pCDNA3-YFP Basic plasmid that had been cut with Kpn1 and Xho1. The amplicon and linearized plasmid backbone were combined using the NEB HiFi DNA Assembly Master Mix (catalog \# E2621L) with 1:2 vector:insert ratios, and 60 min incubation time at $50{ }^{\circ} \mathrm{C}$. The subsequent plasmid was transformed into DH $5 \alpha$ cells. The second method was to insert the amplified construct into a Zero Blunt TOPO vector (Thermo Fisher \#450245), select clones that are in the forward and reverse orientation, then cut the TOPO vector containing the insert with Kpn1 and Xho1. The resulting fragment is then ligated into a digested pCDNA3-YFP Basic plasmid that had been cut with Kpn1 and Xho1 using a standard T4 DNA Ligase protocol (NEB \#M0202). Once the insert, plasmid, and breakpoint sequences were confirmed by Sanger sequencing, the plasmids were extracted from overnight $1 \mathrm{~L}$ cultures of DH5 $\alpha$ cells using Qiagen Plasmid Maxi Kits (catalog \#12163). Endotoxins were removed from the plasmids using the Endotoxin removal Solution (Sigma, E4274-25ML).

\section{RNA-seq}

One million GHF-T1 and T $\alpha \mathrm{T} 1$ cells were collected for each of the three replicates for each cell line. Once collected, the RNA was extracted using the RNAqueous ${ }^{\text {th }}$ Total RNA Isolation Kit (catalog \#AM1912). The RNA was prepared by the University of Michigan Advanced Genomic Core for mRNA enrichment followed by 50cycle, paired-end sequencing on the Illumina HiSeq4000. The RNA was checked for quality using FastQC and mapped and analyzed using the VIPER Snakemake pipeline [81]. Briefly, VIPER aligns the files to the $\mathrm{mm} 9$ transcriptome using STAR, followed by differential expression analysis using DESeq2 and cell type clustering and expression quantification using QoRTs [82]. The quality of the alignment was also analyzed using QoRTs.

We measured the significance of the increase in expression of sodium, potassium, and calcium using a one- way ANOVA. This demonstrated the significance of the increase in expression of the sodium and potassium, but not the calcium channel genes.

\section{GO term and KEGG pathway enrichment}

We performed GO term enrichment on the top 5\% of most differentially expressed genes (by $\log -2$ foldchange) in both lines [32, 33]. This represented 453 genes in GHFT1 cells, and 490 genes in ToT1 cells. We used the default settings on the web-based Gene Ontology Resource (geneontology.org), using the biological process and Mus musculus options. The resulting GO terms were plotted by their $\log -2$ fold enrichment, and their $p$ values.

We also performed a directional Kyoto Encyclopedia of Genes and Genomes (KEGG) pathway enrichment analysis on all of the genes using RNA-enrich [83]. We set the maximum number of genes per concept to 500 and the minimum number of genes per concept to 5 , and otherwise used the default settings. The resulting KEGG pathways were plotted by their coefficients and $p$ values.

\section{ATAC-Seq}

The Assay for Transposase-Accessible Chromatin with high-throughput sequencing (ATAC-seq) was performed as previously described [45, 84]. Briefly, 50,000 nuclei were extracted from collected GHF-T1 and T $\alpha \mathrm{T} 1$ cells. The cells were transposed with Illumina transposase (Illumina \#FC-121-1030) for $30 \mathrm{~min}$ at $37^{\circ} \mathrm{C}$ while shaking at 250 RPM. The resulting fragmented DNA was amplified using $1 / 4$ of the cycles required to reach saturation in the described $\mathrm{qPCR}$ QC. The final amplified DNA library was purified using the Qiagen PCR purification kit (catalog \#28104) and sequenced on the Illumina HiSeq platform. The quality of the reads was checked using FastQC, aligned to the $\mathrm{mm} 9$ genome, and had its peaks called using the Parker lab's Snakemake pipeline [85].

\section{CUT\&RUN}

CUT\&RUN was performed under high-digitonin conditions as described with few exceptions, namely all steps with $<1 \mathrm{ml}$ of liquid requiring mixing were done by 500 RPM shaking instead of inversion [41]. Briefly, 250,000 cells per sample, and one sample per cell line-antibody pair were collected, washed, and bound to Concavalin A beads (Bangs Laboratories, BP531). The cells attached to beads were incubated at $4{ }^{\circ} \mathrm{C}$ overnight with the respective antibodies: POU1F1, Batch\#1603-F, RRID=AB_2722652, provided by Dr. Simon Rhodes, University of North Florida, Jacksonville, FL [86]; H3K27Me3 - Cell Signal \#9733, Batch \#14, RRID=AB_2616029; H3K27Ac - Abcam ab4729, Batch GR3216173-1, RRID = AB_2118291; H3K4Me1 - Abcam ab8895, Batch GR3235544-1, RRID= 
AB_306847; Rabbit IGG - R\&D AB-105-C, RRID $=$ AB 354266). The antibodies were washed, and no secondary antibody was used. The protein A/MNAse fusion protein was added, followed by $\mathrm{Ca}^{2+}$-induced digestion at $0{ }^{\circ} \mathrm{C}$ for $30 \mathrm{~min}$. The fragmented chromatin was then collected and purified using Macherey-Nagel NucleoSpin Gel and cleanup columns (catalog \#740609). Libraries of this DNA was prepared using the Kapa Biosystems library prep kit (catalog \#KK8702) at a 100:1 adapter to sample ratio. The libraries were paired-end sequenced on a single lane of the Illumina HiSeq- 4000 for 50 cycles.

The resulting data was checked for quality using FastQC, aligned to the $\mathrm{mm} 9$ genome using Bowtie 2 using the flags recommended for CUT\&RUN (--local --very-sensitive-local --no-unal --no-mixed --no-discordant --phred33 -I 10 -X 700), and peaks were called using MACS2. We used ENCODE standards for evaluating the quality of our data. One of the metrics is the fraction of reads in peaks, or FRiP, which should correlate with the number of called regions, and it is generally accepted that values should be greater than 1\% [87]. The FRiP values for GHFT1 and T $\alpha \mathrm{T} 1$ cells, respectively, are as follows (in \%): $\mathrm{H} 3 \mathrm{~K} 27 \mathrm{Ac}=21,15 ; \mathrm{H} 3 \mathrm{~K} 4 \mathrm{Me} 1=76,78$; POU1F1 = 32, 23; H3K27Me3 = 4, 6 .

\section{ChromHMM}

ChromHMM was performed on both cell lines using H3K4Me1, H3K27Ac, ATAC-seq, and H3K27Me3 as input. The number of states was iteratively increased to find the number of states that resulted in the fewest number of states with the best log-likelihood. An elevenstate model was selected as a result. Association of each state with the various marks and genomic features can be seen in Supplementary Figure 5. Contiguous states of value two and three were stitched together as enhancers using bedtool's mergeBed function with a -d 1 flag [88].

\section{Association enrichment test}

Enrichment analysis of disease SNPs at stretch en-

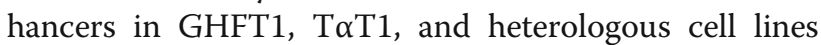
was performed using GARFIELD and stretch enhancers published previously [53, 55]. To find the human sequences orthologous to GHFT1 and T $\alpha \mathrm{T} 1$ stretch enhancers, we used a conversion file generated using bnMapper and an mm9 to hg19 chain file [89]. We selected associations that had association counts of at least 50 , had a full complement of summary statistics, had more than three million tested SNPs, and were in the harmonized data format were chosen from the GWAS catalog [90]. The resulting heatmap of odds ratios and $p$ values for each association, tissue-type pair is shown in Supplementary Figure 7.

\section{Transgenic mice}

All mice were housed in a 12-h light-12-h dark cycle in ventilated cages with unlimited access to tap water and Purina 5020 chow. All procedures were conducted in accordance with the principles and procedures outlined in the National Institutes of Health Guidelines on the Care and Use of Experimental Animals and approved by our Institutional Animal Care and Use Committee.

Recombinant DNA was generated by amplifying genomic mouse DNA regions in Supplemental Table 4, and the previously described Phusion polymerase. The putative regulatory element was then combined with 438 base pairs of the TSH $\beta$ promoter (chr3:102,586,594-102, $587,032)$ and a YFP reporter. These elements were combined using the DNA Hifi reaction into a pGEM-T Easy plasmid. The putative regulatory element, the promoter, the YFP, and the breakpoints were checked for accuracy with Sanger sequencing. Once the plasmid was confirmed, larger quantities of the plasmid were generated from overnight $1 \mathrm{~L}$ cultures of DH5 $\alpha$ cells using Qiagen Plasmid Maxi Kits (catalog \#12163). To reduce the effect of the plasmid backbone on the viability of injected eggs, the enhancer, promoter, and YFP were amplified from the plasmid. The resulting amplicon was gel purified and injected into fertilized eggs of mice on a C57BL/6 and SJL mixed background. The resulting mice were genotyped for the YFP allele according to the Jackson Laboratory recommended primers and conditions [91]. We dissected the pituitaries from mice that were positive for the YFP transgene (and four age-matched, negative, control littermates) at 3 weeks of age.

\section{Tissue preparation and immunohistochemistry}

Mouse pituitaries were fixed in $4 \%$ formaldehyde in PBS overnight at $4{ }^{\circ} \mathrm{C}$. The tissue was washed three times in PBS and put in 10\% EDTA for $3 \mathrm{~h}$. They were then dehydrated by putting them in $25 \%$, then $50 \%$, and then $70 \%$ ethanol for $1 \mathrm{~h}$ each. The pituitaries were embedded in paraffin with 4-h cycles using a Tissue Tek VIP Paraffin tissue processing machine (Miles Scientific). The embedded pituitary was cut into coronal, six-micron sections, and was analyzed by immunohistochemical markers as previously described [22, 92]. Anti-YFP antibody (1:100) was from Abcam ab6556, Batch GR3216572-1, RRID= AB_305564, and anti-Tshb (1:1000) was from the National Hormone and Peptide Program, Batch AFP967793.

Antibodies were detected using either the tyramide signal amplification (TSA) (33002 CFF488A Streptavidin HRP, Biotium, Fremont, CA) and streptavidin-conjugated Alexa-fluor 488 (1:200, S11223, Invitrogen). DAPI (1:200) was incubated on the slides for $5 \mathrm{~min}$ to stain nuclei. DABCO-containing permount was used to mount the slides, which were then imaged using a Leica DMRB fluorescent microscope. To quantify gene expression, a set of 
8-12 slides with pituitary sections were analyzed from each founder mouse. Total TSH positive cells/set were quantified, as well as total YFP-positive, and total doublepositive cells expressing TSH and YFP. A total of 270-872 thyrotropes were counted for two founders.

\section{Supplementary Information}

Supplementary information accompanies this paper at https://doi.org/10. 1186/s12915-021-01009-0.

\section{Additional file 1: Figure S1. Loss of ASCL1 has minimal impact on} thyrotrope number. Figure S2. Multi-omics tracks for loci with similar levels of expression and chromatin landscapes in both cell types. Figure S3. Multi-omics tracks for selected genes with higher levels of expression in GHF-T1 cells. Figure S4. Multi-omics tracks for selected loci with higher levels of expression in TaT1 cells. Figure S5. ChromHMM summary data. Figure S6. Motif density at POU1F1 binding sites in GHF-T1 and TaT1 cells. Figure S7. Heatmap of associations with each cell type. Figure S8. Functional enhancer testing of elements of open chromatin in and around Trhr. Figure S9. Thyrotrope-specific genes identified by single cell sequencing are elevated in TaT1 cells relative to GHF-T1.

Additional file 2: Table S1. Genes Associated with SV40 Immortalized Pituitary Cell Lines. Table S2. bHLH genes expressed in GHF-T1 and TaT1 cells. Table S3. Thyrotrope signature genes. Table S4. Genomic coordinates for promoter and enhancer elements tested in transfection (Mm9). Table S5. Factors with binding motifs in Tshb Element 4. Table S6. Expression of reported thyrotrope-enriched genes in GHF-T1 and TaT1 cells.

\section{Acknowledgements}

We thank Wanda Filipak and Galina Gavrilina of the transgenic animal model core for assistance with the transgenic reporter mice (NIH P30CA046592). We thank Alex Mayran and Jacques Drouin for the advice and pituitaries of Ascl1-null mice. We thank Amanda Mortensen for the genotyping of the founder transgenic reporter mice. We thank Peter Orchard, Arushi Varshney, and Ricardo Albanus for their contributions to the work.

\section{Disclosure declaration}

The authors have nothing to disclose.

\section{Authors' contributions}

AZD performed the RNA-seq, ATAC-seq, and CUT\&RUN (for POU1F1, $\mathrm{H} 3 \mathrm{~K} 27 \mathrm{AC}, \mathrm{H} 3 \mathrm{~K} 4 \mathrm{Me} 1$, and H3K27Me3) library preparation and data analysis. He generated the plasmids and performed the transfections for the luciferase assays. He analyzed the founder reporter mice. LAD performed immunohistochemistry on the Ascl1-null mouse pituitaries. MTP and SAL contributed RNAseq data from Pit1-Zero and Pit1-Triple cell lines. SCJP contributed to the analysis of the high-throughput sequencing data. SAC led the experimental design. SAC and AZD wrote the manuscript together with input from SCJP. All authors read and approved the final manuscript.

\section{Funding}

NIH R01HD034283 (SAC), NIH T32GM007544, and T32HG000040 (AZD).

\section{Availability of data and materials}

All data generated or analyzed during this study are included in this published article, its supplementary information files and publicly available repositories. All raw sequencing data generated in this study have been submitted to the NCBI Sequence Read Archive (SRA, https://www.ncbi.nlm. nih.gov/sra) under accession number PRJNA643917, SUB7682741.

\section{Competing interests}

The authors declare that they have no competing interests.

\section{Author details}

'Department Human Genetics, University of Michigan Medical School, Ann Arbor, MI 48109, USA. ²Department Genetics, University of Pennsylvania Perelman School of Medicine, Ann Arbor, MI 48109, USA. ${ }^{3}$ Incyte, Wilmington, DE 19803, USA. ${ }^{4}$ Department Computational Medicine and
Bioinformatics, University of Michigan Medical School, Ann Arbor, Ml 48109 USA.

Received: 22 September 2020 Accepted: 23 March 2021

Published online: 15 April 2021

\section{References}

1. Jarvis JP, Scheinfeldt LB, Soi S, Lambert C, Omberg L, Ferwerda B, Froment A, Bodo JM, Beggs W, Hoffman G, Mezey J, Tishkoff SA. Patterns of ancestry, signatures of natural selection, and genetic association with stature in Western African pygmies. PLoS Genet. 2012;8(4):e1002641. https://doi.org/1 0.1371/journal.pgen.1002641.

2. Turchin MC, Chiang CW, Palmer CD, Sankararaman S, Reich D, Genetic Investigation of ATC, Hirschhorn JN. Evidence of widespread selection on standing variation in Europe at height-associated SNPs. Nat Genet. 2012; 44(9):1015-9. https://doi.org/10.1038/ng.2368.

3. Ye Z, Li Z, Wang Y, Mao Y, Shen M, Zhang Q, Li S, Zhou L, Shou X, Chen J, Song Z, Ma Z, Zhang Z, Li Y, Ye H, Huang C, Wang T, He W, Zhang Y, Xie R, Qiao N, Qiu H, Huang S, Wang M, Shen J, Wen Z, Li W, Liu K, Zhou J, Wang L, Ji J, Wang Y, Chen H, Cheng H, Shi Z, Zhu Y, Geng D, Yao Z, Tang W, Lu B, Pan L, Zhang Y, Bao W, Wu J, Zheng K, Shi Y, Zhao Y. Common variants at 10p12.31, 10q21.1 and 13q12.13 are associated with sporadic pituitary adenoma. Nat Genet. 2015;47(7):793-7. https://doi.org/10.1038/ng.3322.

4. Edwards SL, Beesley J, French JD, Dunning AM. Beyond GWASs: illuminating the dark road from association to function. Am J Hum Genet. 2013;93(5): 779-97. https://doi.org/10.1016/j.ajhg.2013.10.012.

5. Mayran A, Khetchoumian K, Hariri F, Pastinen T, Gauthier Y, Balsalobre A, Drouin J. Pioneer factor Pax7 deploys a stable enhancer repertoire for specification of cell fate. Nat Genet. 2018;50(2):259-69. https://doi.org/10.103 8/s41588-017-0035-2.

6. Mayran A, Sochodolsky K, Khetchoumian K, Harris J, Gauthier Y, Bemmo A, Balsalobre A, Drouin J. Pioneer and nonpioneer factor cooperation drives lineage specific chromatin opening. Nat Commun. 2019;10(1):3807. https:// doi.org/10.1038/s41467-019-11791-9.

7. Peel MT, Ho Y, Liebhaber SA. Transcriptome analyses of female Somatotropes and Lactotropes reveal novel regulators of cell identity in the pituitary. Endocrinology. 2018;159(12):3965-80. https://doi.org/10.1210/en.2 018-00587.

8. Qiao S, Nordstrom K, Muijs L, Gasparoni G, Tierling S, Krause E, Walter J, Boehm U. Molecular plasticity of male and female murine Gonadotropes revealed by mRNA sequencing. Endocrinology. 2016;157(3):1082-93. https:// doi.org/10.1210/en.2015-1836.

9. Canaris GJ, Manowitz NR, Mayor G, Ridgway EC. The Colorado thyroid disease prevalence study. Arch Intern Med. 2000;160(4):526-34. https://doi. org/10.1001/archinte.160.4.526.

10. Persani $L$, Cangiano B, Bonomi M. The diagnosis and management of central hypothyroidism in 2018. Endocr Connect. 2019;8(2):R44-54. https:// doi.org/10.1530/EC-18-0515.

11. Li S, Crenshaw EB 3rd, Rawson EJ, Simmons DM, Swanson LW, Rosenfeld MG. Dwarf locus mutants lacking three pituitary cell types result from mutations in the POU-domain gene pit-1. Nature. 1990;347(6293):528-33. https://doi.org/10.1038/347528a0.

12. Bodner M, Karin M. A pituitary-specific trans-acting factor can stimulate transcription from the growth hormone promoter in extracts of nonexpressing cells. Cell. 1987;50(2):267-75. https://doi.org/10.1016/00928674(87)90222-4.

13. Gordon DF, Lewis SR, Haugen BR, James RA, McDermott MT, Wood WM Ridgway EC. Pit-1 and GATA-2 interact and functionally cooperate to activate the thyrotropin beta-subunit promoter. J Biol Chem. 1997;272(39): 24339-47. https://doi.org/10.1074/jbc.272.39.24339.

14. Hashimoto K, Zanger K, Hollenberg AN, Cohen LE, Radovick S, Wondisford FE. CAMP response element-binding protein-binding protein mediates thyrotropin-releasing hormone signaling on thyrotropin subunit genes. J Biol Chem. 2000;275(43):33365-72. https://doi.org/10.1074/jbc.M006819200.

15. Ingraham HA, Chen RP, Mangalam HJ, Elsholtz HP, Flynn SE, Lin CR, Simmons DM, Swanson L, Rosenfeld MG. A tissue-specific transcription factor containing a homeodomain specifies a pituitary phenotype. Cell. 1988;55(3):519-29. https://doi.org/10.1016/0092-8674(88)90038-4.

16. Wood WM, Dowding JM, Gordon DF, Ridgway EC. An upstream regulator of the glycoprotein hormone alpha-subunit gene mediates pituitary cell type 
activation and repression by different mechanisms. J Biol Chem. 1999; 274(22):15526-32. https://doi.org/10.1074/jbc.274.22.15526.

17. Fang $Q$, George AS, Brinkmeier ML, Mortensen AH, Gergics P, Cheung LY, Daly AZ, Ajmal A, Perez Millan Ml, Ozel AB, et al. Genetics of combined pituitary hormone deficiency: roadmap into the genome era. Endocr Rev. 2016:37(6):636-75. https://doi.org/10.1210/er.2016-1101.

18. Dasen JS, O'Connell SM, Flynn SE, Treier M, Gleiberman AS, Szeto DP, Hooshmand F, Aggarwal AK, Rosenfeld MG. Reciprocal interactions of Pit1 and GATA2 mediate signaling gradient-induced determination of pituitary cell types. Cell. 1999;97(5):587-98. https://doi.org/10.1016/S0092-8674 (00)80770-9.

19. Brinkmeier ML, Bando H, Camarano AC, Fujio S, Yoshimoto K, de Souza FSJ, Camper SA. Rathke's cleft-like cysts arise from Isl1 deletion in murine pituitary progenitors. J Clin Invest. 2020; https://doi.org/10.1172/JCI136745.

20. Castinetti F, Brinkmeier ML, Mortensen AH, Vella KR, Gergics P, Brue T, Hollenberg AN, Gan L, Camper SA. ISL1 is necessary for maximal thyrotrope response to hypothyroidism. Mol Endocrinol. 2015;29(10):1510-21. https:// doi.org/10.1210/me.2015-1192.

21. Charles MA, Saunders TL, Wood WM, Owens K, Parlow AF, Camper SA, Ridgway EC, Gordon DF. Pituitary-specific Gata2 knockout: effects on gonadotrope and thyrotrope function. Mol Endocrinol. 2006;20(6):1366-77. https://doi.org/10.1210/me.2005-0378.

22. Castinetti F, Brinkmeier ML, Gordon DF, Vella KR, Kerr JM, Mortensen AH, Hollenberg A, Brue T, Ridgway EC, Camper SA. PITX2 AND PITX1 regulate thyrotroph function and response to hypothyroidism. Mol Endocrinol. 2011; 25(11):1950-60. https://doi.org/10.1210/me.2010-0388.

23. Szeto DP, Rodriguez-Esteban C, Ryan AK, O'Connell SM, Liu F, Kioussi C, Gleiberman AS, Izpisua-Belmonte JC, Rosenfeld MG. Role of the Bicoidrelated homeodomain factor Pitx 1 in specifying hindlimb morphogenesis and pituitary development. Genes Dev. 1999;13(4):484-94. https://doi.org/1 0.1101/gad.13.4.484.

24. Charles MA, Suh H, Hjalt TA, Drouin J, Camper SA, Gage PJ. PITX genes are required for cell survival and Lhx3 activation. Mol Endocrinol. 2005;19(7): 1893-903. https://doi.org/10.1210/me.2005-0052.

25. Budry L, Balsalobre A, Gauthier Y, Khetchoumian K, L'Honore A, Vallette S, Brue T, Figarella-Branger D, Meij B, Drouin J. The selector gene Pax7 dictates alternate pituitary cell fates through its pioneer action on chromatin remodeling. Genes Dev. 2012;26(20):2299-310. https://doi.org/10.1101/gad.2 00436.112.

26. Alarid ET, Windle JJ, Whyte DB, Mellon PL. Immortalization of pituitary cells at discrete stages of development by directed oncogenesis in transgenic mice. Development. 1996;122(10):3319-29.

27. Lew D, Brady H, Klausing K, Yaginuma K, Theill LE, Stauber C, Karin M, Mellon PL. GHF-1-promoter-targeted immortalization of a somatotropic progenitor cell results in dwarfism in transgenic mice. Genes Dev. 1993;7(4): 683-93. https://doi.org/10.1101/gad.7.4.683.

28. Aninye IO, Matsumoto S, Sidhaye AR, Wondisford FE. Circadian regulation of Tshb gene expression by rev-Erbalpha (NR1D1) and nuclear corepressor 1 (NCOR1). J Biol Chem. 2014;289(24):17070-7. https://doi.org/10.1074/jbc. M114.569723.

29. Janssen JS, Sharma V, Pugazhenthi U, Sladek C, Wood WM, Haugen BR. A rexinoid antagonist increases the hypothalamic-pituitary-thyroid set point in mice and thyrotrope cells. Mol Cell Endocrinol. 2011;339(1-2):1-6. https:// doi.org/10.1016/j.mce.2011.03.014

30. Nakajima Y, Yamada M, Taguchi R, Shibusawa N, Ozawa A, Tomaru T, Hashimoto K, Saito T, Tsuchiya T, Okada S, Satoh T, Mori M. NR4A1 (Nur77) mediates thyrotropin-releasing hormone-induced stimulation of transcription of the thyrotropin beta gene: analysis of TRH knockout mice. PLoS One. 2012;7(7):e40437. https://doi.org/10.1371/journal.pone.0040437.

31. Sizova D, Ho Y, Cooke NE, Liebhaber SA. Research resource: T-antigen transformation of pituitary cells captures three novel cell lines in the Pit-1 lineage. Mol Endocrinol. 2010;24(11):2232-40. https://doi.org/10.1210/me.2 010-0235.

32. Ashburner M, Ball CA, Blake JA, Botstein D, Butler H, Cherry JM, Davis AP, Dolinski K, Dwight SS, Eppig JT, Harris MA, Hill DP, Issel-Tarver L, Kasarskis A, Lewis S, Matese JC, Richardson JE, Ringwald M, Rubin GM, Sherlock G. Gene ontology: tool for the unification of biology. The Gene Ontology Consortium. Nat Genet. 2000;25(1):25-9. https://doi.org/10.1038/75556.

33. The Gene Ontology C. The Gene Ontology Resource: 20 years and still GOing strong. Nucleic Acids Res. 2019;47(D1):D330-8.
34. Carreno G, Apps JR, Lodge EJ, Panousopoulos L, Haston S, Gonzalez-Meljem JM, Hahn H, Andoniadou CL, Martinez-Barbera JP. Hypothalamic sonic hedgehog is required for cell specification and proliferation of LHX3/LHX4 pituitary embryonic precursors. Development. 2017;144(18):3289-302. https://doi.org/10.1242/dev.153387.

35. Ericson J, Norlin S, Jessell TM, Edlund T. Integrated FGF and BMP signaling controls the progression of progenitor cell differentiation and the emergence of pattern in the embryonic anterior pituitary. Development. 1998;125(6):1005-15.

36. Treier M, O'Connell S, Gleiberman A, Price J, Szeto DP, Burgess R, Chuang PT, McMahon AP, Rosenfeld MG. Hedgehog signaling is required for pituitary gland development. Development. 2001;128(3):377-86.

37. Fletcher PA, Sherman A, Stojilkovic SS. Common and diverse elements of ion channels and receptors underlying electrical activity in endocrine pituitary cells. Mol Cell Endocrinol. 2018;463:23-36. https://doi.org/10.1016/j. mce.2017.06.022.

38. Le Tissier P, Fiordelisio Coll T, Mollard P. The processes of anterior pituitary hormone pulse generation. Endocrinology. 2018;159(10):3524-35. https:// doi.org/10.1210/en.2018-00508.

39. Ando M, Goto M, Hojo M, Kita A, Kitagawa M, Ohtsuka T, Kageyama R, Miyamoto S. The proneural bHLH genes Mash1, Math3 and NeuroD are required for pituitary development. J Mol Endocrinol. 2018;61(3):127-38. https://doi.org/10.1530/JME-18-0090.

40. Zhang F, Tanasa B, Merkurjev D, Lin C, Song X, Li W, Tan Y, Liu Z, Zhang J, Ohgi KA, Krones A, Skowronska-Krawczyk D, Rosenfeld MG. Enhancer-bound LDB1 regulates a corticotrope promoter-pausing repression program. Proc Natl Acad Sci U S A. 2015;112(5):1380-5. https://doi.org/10.1073/pna S.1424228112.

41. Skene PJ, Henikoff S. An efficient targeted nuclease strategy for highresolution mapping of DNA binding sites. Elife. 2017;6 https://doi.org/10. 7554/eLife.21856.

42. Boyer LA, Plath K, Zeitlinger J, Brambrink T, Medeiros LA, Lee TI, Levine SS, Wernig M, Tajonar A, Ray MK, Bell GW, Otte AP, Vidal M, Gifford DK, Young RA, Jaenisch R. Polycomb complexes repress developmental regulators in murine embryonic stem cells. Nature. 2006;441 (7091):349-53. https://doi. org/10.1038/nature04733.

43. Bracken AP, Dietrich N, Pasini D, Hansen KH, Helin K. Genome-wide mapping of Polycomb target genes unravels their roles in cell fate transitions. Genes Dev. 2006;20(9):1123-36. https://doi.org/10.1101/gad.381706.

44. Creyghton MP, Cheng AW, Welstead GG, Kooistra T, Carey BW, Steine EJ, Hanna J, Lodato MA, Frampton GM, Sharp PA, Boyer LA, Young RA, Jaenisch R. Histone H3K27ac separates active from poised enhancers and predicts developmental state. Proc Natl Acad Sci U S A. 2010;107(50):21931-6. https://doi.org/10.1073/pnas.1016071107.

45. Buenrostro JD, Giresi PG, Zaba LC, Chang HY, Greenleaf WJ. Transposition of native chromatin for fast and sensitive epigenomic profiling of open chromatin, DNA-binding proteins and nucleosome position. Nat Methods. 2013;10(12):1213-8. https://doi.org/10.1038/nmeth.2688.

46. Brown NS, Smart A, Sharma V, Brinkmeier ML, Greenlee L, Camper SA, Jensen DR, Eckel RH, Krezel W, Chambon P, Haugen BR. Thyroid hormone resistance and increased metabolic rate in the RXR-gamma-deficient mouse. J Clin Invest. 2000;106(1):73-9. https://doi.org/10.1172/JCl9422.

47. Cheung LYM, Camper SA. PROP1-dependent retinoic acid signaling regulates developmental pituitary morphogenesis and hormone expression. Endocrinology. 2020;161(2):1-13.

48. Ernst J, Kellis M. ChromHMM: automating chromatin-state discovery and characterization. Nat Methods. 2012;9(3):215-6. https://doi.org/10.1038/ nmeth. 1906.

49. Chen RP, Ingraham HA, Treacy MN, Albert VR, Wilson L, Rosenfeld MG. Autoregulation of pit-1 gene expression mediated by two cis-active promoter elements. Nature. 1990;346(6284):583-6. https://doi.org/10.103 8/346583a0.

50. DiMattia GE, Rhodes SJ, Krones A, Carriere C, O'Connell S, Kalla K, Arias C, Sawchenko P, Rosenfeld MG. The Pit-1 gene is regulated by distinct early and late pituitary-specific enhancers. Dev Biol. 1997;182(1):180-90. https:// doi.org/10.1006/dbio.1996.8472.

51. Gaston-Massuet C, McCabe MJ, Scagliotti V, Young RM, Carreno G, Gregory LC, Jayakody SA, Pozzi S, Gualtieri A, Basu B, et al. Transcription factor 7-like 1 is involved in hypothalamo-pituitary axis development in mice and humans. Proc Natl Acad Sci U S A. 2016;113(5):E548-57. https://doi.org/10.1 073/pnas.1503346113. 
52. Castronovo P, Baccarin M, Ricciardello A, Picinelli C, Tomaiuolo P, Cucinotta F, Frittoli M, Lintas C, Sacco R, Persico AM. Phenotypic spectrum of NRXN1 mono- and bi-allelic deficiency: a systematic review. Clin Genet. 2020;97(1): 125-37. https://doi.org/10.1111/cge.13537.

53. Parker SC, Stitzel ML, Taylor DL, Orozco JM, Erdos MR, Akiyama JA, van Bueren KL, Chines PS, Narisu N, Program NCS, et al. Chromatin stretch enhancer states drive cell-specific gene regulation and harbor human disease risk variants. Proc Natl Acad Sci U S A. 2013;110(44):17921-6. https:// doi.org/10.1073/pnas.1317023110.

54. Varshney A, VanRenterghem H, Orchard P, Boyle AP, Stitzel ML, Ucar D, Parker SCJ. Cell specificity of human regulatory annotations and their genetic effects on gene expression. Genetics. 2019;211(2):549-62. https:// doi.org/10.1534/genetics.118.301525.

55. lotchkova V, Ritchie GRS, Geihs M, Morganella S, Min JL, Walter K, Timpson NJ, Consortium UK, Dunham I, Birney E, et al. GARFIELD classifies diseaserelevant genomic features through integration of functional annotations with association signals. Nat Genet. 2019;51(2):343-53. https://doi.org/10.103 8/s41588-018-0322-6.

56. Nagel M, Watanabe K, Stringer S, Posthuma D, van der Sluis S. Item-level analyses reveal genetic heterogeneity in neuroticism. Nat Commun. 2018; 9(1):905. https://doi.org/10.1038/s41467-018-03242-8.

57. Minegishi N, Ohta J, Suwabe N, Nakauchi H, Ishihara H, Hayashi N, Yamamoto M. Alternative promoters regulate transcription of the mouse GATA-2 gene. J Biol Chem. 1998;273(6):3625-34. https://doi.org/10.1074/ jbc.273.6.3625.

58. Kendall SK, Gordon DF, Birkmeier TS, Petrey D, Sarapura VD, O'Shea KS, Wood WM, Lloyd RV, Ridgway EC, Camper SA. Enhancer-mediated high level expression of mouse pituitary glycoprotein hormone alpha-subunit transgene in thyrotropes, gonadotropes, and developing pituitary gland. Mol Endocrinol. 1994;8(10):1420-33.

59. Brinkmeier ML, Gordon DF, Dowding JM, Saunders TL, Kendall SK, Sarapura VD, Wood WM, Ridgway EC, Camper SA. Cell-specific expression of the mouse glycoprotein hormone alpha-subunit gene requires multiple interacting DNA elements in transgenic mice and cultured cells. Mol Endocrinol. 1998;12(5):622-33. https://doi.org/10.1210/mend.12.5.0103.

60. Daly AZ, Camper SA. Pituitary Development and Organogenesis: Transcription Factors in Development and Disease. In: Wray S, Blackshaw S, editors. Developmental Neuroendocrinology. Cham: Springer International Publishing; 2020. p. 129-77.

61. Lamonerie T, Tremblay JJ, Lanctot C, Therrien M, Gauthier Y, Drouin J. Ptx1, a bicoid-related homeo box transcription factor involved in transcription of the pro-opiomelanocortin gene. Genes Dev. 1996;10(10):1284-95. https:// doi.org/10.1101/gad.10.10.1284

62. Kragesteen BK, Brancati F, Digilio MC, Mundlos S, Spielmann M. H2AFY promoter deletion causes PITX1 endoactivation and Liebenberg syndrome. J Med Genet. 2019;56(4):246-51. https://doi.org/10.1136/jmedgenet-2018-1 05793.

63. Camper SA, Saunders TL, Kendall SK, Keri RA, Seasholtz AF, Gordon DF, Birkmeier TS, Keegan CE, Karolyi IJ, Roller ML, et al. Implementing transgenic and embryonic stem cell technology to study gene expression, cell-cell interactions and gene function. Biol Reprod. 1995;52(2):246-57. https://doi. org/10.1095/biolreprod52.2.246.

64. Cheung LYM, George AS, McGee SR, Daly AZ, Brinkmeier ML, Ellsworth BS, Camper SA. Single-cell RNA sequencing reveals novel markers of male pituitary stem cells and hormone-producing cell types. Endocrinology. 2018; 159(12):3910-24. https://doi.org/10.1210/en.2018-00750.

65. Fletcher PA, Smiljanic K, Maso Previde R, Iben JR, Li T, Rokic MB, Sherman A, Coon SL, Stojilkovic SS. Cell type- and sex-dependent Transcriptome profiles of rat anterior pituitary cells. Front Endocrinol (Lausanne). 2019;10:623. https://doi.org/10.3389/fendo.2019.00623.

66. Zhang S, Cui Y, Ma X, Yong J, Yan L, Yang M, Ren J, Tang F, Wen L, Qiao J. Single-cell transcriptomics identifies divergent developmental lineage trajectories during human pituitary development. Nat Commun. 2020;11(1): 5275. https://doi.org/10.1038/s41467-020-19012-4.

67. Khetchoumian K, Balsalobre A, Mayran A, Christian H, Chenard V, St-Pierre J, Drouin J. Pituitary cell translation and secretory capacities are enhanced cell autonomously by the transcription factor Creb312. Nat Commun. 2019;10(1): 3960. https://doi.org/10.1038/s41467-019-11894-3.

68. Gergics P, Christian HC, Choo MS, Ajmal A, Camper SA. Gene expression in mouse thyrotrope adenoma: transcription elongation factor stimulates proliferation. Endocrinology. 2016;157(9):3631-46. https://doi.org/10.1210/ en.2016-1183.

69. Mollard P, Dufy B, Vacher P, Barker $J$, Schlegel W. Thyrotropin-releasing hormone activates a [Ca2+]i-dependent $\mathrm{K}+$ current in $\mathrm{GH} 3$ pituitary cells via ins $(1,4,5)$ P3-sensitive and ins $(1,4,5)$ P3-insensitive mechanisms. Biochem J. 1990;268(2):345-52. https://doi.org/10.1042/bj2680345.

70. Tomic M, Bargi-Souza P, Leiva-Salcedo E, Nunes MT, Stojilkovic SS. Calcium signaling properties of a thyrotroph cell line, mouse TalphaT1 cells. Cell Calcium. 2015;58(6):598-605. https://doi.org/10.1016/j.ceca.2015.09.003.

71. Tommiska J, Kansakoski J, Skibsbye L, Vaaralahti K, Liu X, Lodge EJ, Tang C, Yuan L, Fagerholm R, Kanters JK, et al. Two missense mutations in KCNQ1 cause pituitary hormone deficiency and maternally inherited gingival fibromatosis. Nat Commun. 2017;8(1):1289. https://doi.org/10.1038/s41467017-01429-z.

72. Sheng HZ, Moriyama K, Yamashita T, Li H, Potter SS, Mahon KA, Westphal H. Multistep control of pituitary organogenesis. Science. 1997;278(5344):180912. https://doi.org/10.1126/science.278.5344.1809.

73. Mortensen AH, Daly AZ, Dudley LA, Camper SA. Pituitary tumors and immortalized cell lines generated by cre-inducible expression of SV40 Tantigen. J Endocr Soc. 2020;4(OR-06-06):A901.

74. Ait-Lounis A, Baas D, Barras E, Benadiba C, Charollais A, Nlend Nlend R, Liegeois D, Meda P, Durand B, Reith W. Novel function of the ciliogenic transcription factor RFX3 in development of the endocrine pancreas. Diabetes. 2007:56(4):950-9. https://doi.org/10.2337/db06-1187.

75. Elkon R, Milon B, Morrison L, Shah M, Vijayakumar S, Racherla M, Leitch CC, Silipino L, Hadi S, Weiss-Gayet M, Barras E, Schmid CD, Ait-Lounis A, Barnes A, Song Y, Eisenman DJ, Eliyahu E, Frolenkov Gl, Strome SE, Durand B, Zaghloul NA, Jones SM, Reith W, Hertzano R. RFX transcription factors are essential for hearing in mice. Nat Commun. 2015;6(1):8549. https://doi.org/1 0.1038/ncomms9549.

76. Brinkmeier ML, Davis SW, Carninci P, MacDonald JW, Kawai J, Ghosh D, Hayashizaki Y, Lyons RH, Camper SA. Discovery of transcriptional regulators and signaling pathways in the developing pituitary gland by bioinformatic and genomic approaches. Genomics. 2009;93(5):449-60. https://doi.org/10.1 016/j.ygeno.2008.11.010.

77. Herzog W, Sonntag C, Walderich B, Odenthal J, Maischein HM, Hammerschmidt M. Genetic analysis of adenohypophysis formation in zebrafish. Mol Endocrinol. 2004;18(5):1185-95. https://doi.org/10.1210/me.2 003-0376.

78. Pogoda HM, von der Hardt S, Herzog W, Kramer C, Schwarz H, Hammerschmidt M. The proneural gene ascl1a is required for endocrine differentiation and cell survival in the zebrafish adenohypophysis. Development. 2006;133(6):1079-89. https://doi.org/10.1242/dev.02296.

79. Avilion AA, Nicolis SK, Pevny LH, Perez L, Vivian N, Lovell-Badge R. Multipotent cell lineages in early mouse development depend on SOX2 function. Genes Dev. 2003;17(1):126-40. https://doi.org/10.1101/gad.224503.

80. Gregory LC, Dattani MT. The molecular basis of congenital hypopituitarism and related disorders. J Clin Endocrinol Metab. 2020;105(6):e2103-e2120.

81. Cornwell M, Vangala M, Taing L, Herbert Z, Koster J, Li B, Sun H, Li T, Zhang J, Qiu X, et al. VIPER: visualization pipeline for RNA-seq, a Snakemake workflow for efficient and complete RNA-seq analysis. BMC Bioinformatics. 2018;19(1):135. https://doi.org/10.1186/s12859-018-2139-9.

82. Hartley SW, Mullikin JC. QoRTs: a comprehensive toolset for quality control and data processing of RNA-Seq experiments. BMC Bioinformatics. 2015; 16(1):224. https://doi.org/10.1186/s12859-015-0670-5.

83. Lee C, Patil S, Sartor MA. RNA-enrich: a cut-off free functional enrichment testing method for RNA-seq with improved detection power. Bioinformatics. 2016;32(7):1100-2. https://doi.org/10.1093/bioinformatics/ btv694.

84. Buenrostro JD, Wu B, Chang HY, Greenleaf WJ. ATAC-seq: a method for assaying chromatin accessibility genome-wide. Curr Protoc Mol Biol. 2015; 109:21 29 21-9.

85. Rai V, Quang DX, Erdos MR, Cusanovich DA, Daza RM, Narisu N, Zou LS, Didion JP, Guan Y, Shendure J, Parker SCJ, Collins FS. Single-cell ATAC-Seq in human pancreatic islets and deep learning upscaling of rare cells reveals cell-specific type 2 diabetes regulatory signatures. Mol Metab. 2020;32:10921. https://doi.org/10.1016/j.molmet.2019.12.006.

86. Prince KL, Colvin SC, Park S, Lai X, Witzmann FA, Rhodes SJ. Developmental analysis and influence of genetic background on the Lhx3 W227ter mouse model of combined pituitary hormone deficiency disease. Endocrinology. 2013;154(2):738-48. https://doi.org/10.1210/en.2012-1790. 
87. Landt SG, Marinov GK, Kundaje A, Kheradpour P, Pauli F, Batzoglou S, Bernstein BE, Bickel P, Brown JB, Cayting P, Chen Y, DeSalvo G, Epstein C, Fisher-Aylor Kl, Euskirchen G, Gerstein M, Gertz J, Hartemink AJ, Hoffman MM, lyer VR, Jung YL, Karmakar S, Kellis M, Kharchenko PV, Li Q, Liu T, Liu XS, Ma L, Milosavljevic A, Myers RM, Park PJ, Pazin MJ, Perry MD, Raha D, Reddy TE, Rozowsky J, Shoresh N, Sidow A, Slattery M, Stamatoyannopoulos JA, Tolstorukov MY, White KP, Xi S, Farnham PJ, Lieb JD, Wold BJ, Snyder M. ChIP-seq guidelines and practices of the ENCODE and modENCODE consortia. Genome Res. 2012;22(9):1813-31. https://doi.org/10.1101/gr.1361 84.111.

88. Quinlan AR, Hall IM. BEDTools: a flexible suite of utilities for comparing genomic features. Bioinformatics. 2010;26(6):841-2. https://doi.org/10.1093/ bioinformatics/btq033.

89. Orchard P, White JS, Thomas PE, Mychalowych A, Kiseleva A, Hensley J, Allen B, Parker SCJ, Keegan CE. Genome-wide chromatin accessibility and transcriptome profiling show minimal epigenome changes and coordinated transcriptional dysregulation of hedgehog signaling in Danforth's short tail mice. Hum Mol Genet. 2019;28(5):736-50. https://doi.org/10.1093/hmg/ddy378.

90. Buniello A, MacArthur JAL, Cerezo M, Harris LW, Hayhurst J, Malangone C, McMahon A, Morales J, Mountjoy E, Sollis E, et al. The NHGRI-EBI GWAS catalog of published genome-wide association studies, targeted arrays and summary statistics 2019. Nucleic Acids Res. 2019;47(D1):D1005-12. https:// doi.org/10.1093/nar/gky1120.

91. Srinivas S, Watanabe T, Lin CS, William CM, Tanabe Y, Jessell TM, Costantin F. Cre reporter strains produced by targeted insertion of EYFP and ECFP into the ROSA26 locus. BMC Dev Biol. 2001;1(1):4. https://doi.org/10.1186/14 71-213X-1-4

92. Mortensen AH, Schade V, Lamonerie T, Camper SA. Deletion of OTX2 in neural ectoderm delays anterior pituitary development. Hum Mol Genet. 2015;24(4):939-53. https://doi.org/10.1093/hmg/ddu506.

\section{Publisher's Note}

Springer Nature remains neutral with regard to jurisdictional claims in published maps and institutional affiliations.

Ready to submit your research? Choose BMC and benefit from:

- fast, convenient online submission

- thorough peer review by experienced researchers in your field

- rapid publication on acceptance

- support for research data, including large and complex data types

- gold Open Access which fosters wider collaboration and increased citations

- maximum visibility for your research: over $100 \mathrm{M}$ website views per year

At $\mathrm{BMC}$, research is always in progress.

Learn more biomedcentral.com/submissions 